\title{
UNIIED STATES
}

DRPARTMENT OF TEE INTIRIOR

GEOIOGICAI SURVEY

INTERAGENCY REPORT NASA-159

TESTING THE FRAUNHOFER LINT DISCRIMINATOR

BY SENSING FLUORESCENP DYE*

(NASA-CR-125653) TESTING THE FRAUNHOFER

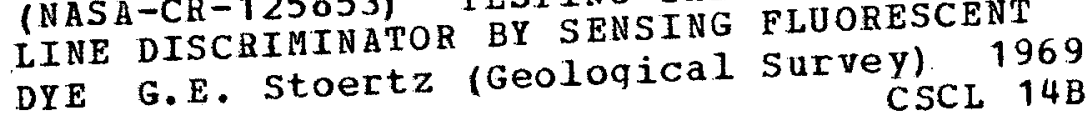
$53 \mathrm{p}$
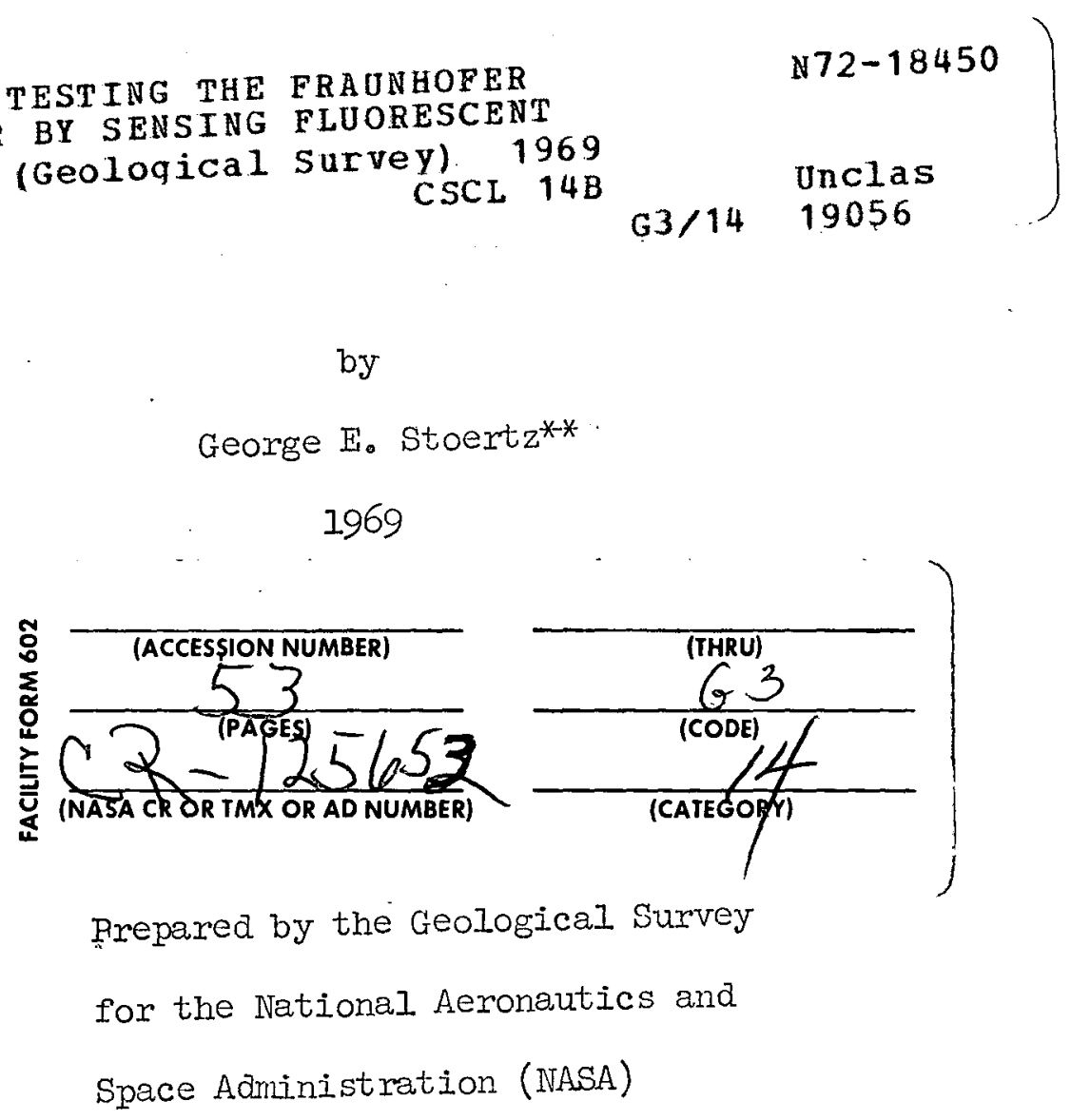

* Work performed under IVASA Work order No. T-80485C, Task 160-75-03-12-TA2511-TF41 **U. S. Geological Survey, Washington, D. C. 


\section{NOTICE}

On reproduction of this report, the quality of the illustrations may not be preserved. Full-gige originel copies of this report may be reviewed by the public at the libraries of the following U. S. Geological Survey locations:

U. S. Geological Survey 1033 General Services Administration Bldg. Washington DC 20242

U.S. Geological Survey $601 \mathrm{E}$. Cedar Avenue Flagstaff, Arizona 86002

U.S. Geological Survey 345 Middlefield Road Menlo Park, California 94025

U.S. Geological Survey Bldg. 25, Denver Federal Center Denver, Colorado 80225

It is advisable to inquire concerning the timely availability of the original of this report and the possible utilization of local copying services before visiting a particular library.

There are no color illustrations in this report. 
Abstract ..................................... ${ }_{i}$

Initial tests of use of FLD to measure Rhodamine WT dye concentration . 1

General methods ................... 1

Relation of luminescence coefficient to concentration of

Rhodamine WT dye................... 2 2.

Relation of luminescence coefficient to depth of Rhodamine

WT dye solution.................. 5

Relation of luminescence coefficient to angle of the sun's rays . . 8

Relation of luminescence coefficient to temperature of Rhodamine

WT dye solutions ................ 10

Relation of luminescence coefficient to turbidity of solution . . . 11

Other results of testing of the FLD ............. 13

Plans for further testing of FLD and anticipated results . . . . . . . 16

Testing of threshold sensitivity ............ 17

Testing of linearity of output as function of luminescence signal . 19

Testing of electronic noise ............... 21

Testing of minimum detectable incremental variations in luminescence signal ............... 23

Testing of instrumental drift . . . . . . . . . . . 24

Testing of effects of temperature and vibration . . . . . . 25

Testing effects of altitude and field-of-view . . . . . . . 27

Testing of effects of haze and clouds . . . . . . . . 30 
Testing of effects of sun angle .............. 31

Testing of signal noise in crossing targets of varying reflectivity . . 32

Testing dispersion characteristics of Rhodamine WT dye in water . . 33

Testing luminescence signal as a function of depth in water of the luminescence producing dye . . . . . . . . . 33

Testing attenuation of incident radiation and luminescence emission as a function of depth . . . . . . . . . . . . 34

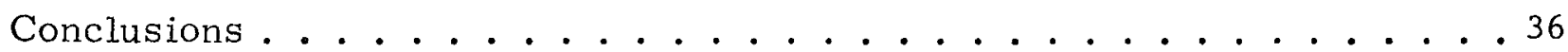

References cited .................. 40

\section{ILLUSTRATIONS}

Figure 1. View of optical sensing unit of the Fraunhofer Line Discriminator

2. Strip-chart from dye concentration test of FLD on October 29, showing 17 successive increments averaging 3.2 parts per billion of Rhodamine WT dye

3. Relation of luminescence coefficient ( $\underline{\text { rho })}$ to concentration of Rhodamine WT dye in $1 / 2$ meter of water, as sensed by the FLD (dye concentration test of October 29)

4. Relation between luminescence coefficient (rho) and height of dye column illuminated by sunlight, as sensed by the FLD (depth test of November 1)

5. Relation between luminescence coefficient (rho) and height of dye column sensed by the FLD (lucite-cylinder depth test of October 29)

6. Relation between luminescence coefficient ( $\underline{\text { rho }}$ ) and depth of dye solution in the range from 1 inch to 19 inches as sensed by the FLD (opaque-plate depth test of October 27)

7. Sun angles during FLD tests and relation to reflectance from calm water

8. Relation between luminescence coefficient $(\underline{\mathrm{rho}})$ and temperature in 
$1 / 2$ meter of rhodamine dye solution, as sensed by the FLD (temperature test of October 27)

9. Apparent relation between length of FLD light-collector tube and noise in record of luminescence coefficient (observed on October 10)

10. Spurious "luminescence coefficients" recorded by FLD from nonluminescent reflective materials, showing dependence of signal on orientation of the material (reflectivity test of November 2)

11. Relation of heavy cirrus clouds to luminescence coefficient (rho) recorded by FLD (observed on October 31)

12. Sketch showing planned plexiglas-box experiment for testing luminescence signal as a function of depth in water

Table 1. Percentage loss of fluorescence caused by adsorption of Rhodamine WT dye on sand and silt particles (from Watt, 1965) 


\section{A stract}

The experimental Fraunhofer Line Discriminator (FLD) has detected increments of Rhodamine WT dye as small as 1 ppb in $1 / 2$ meter depths. It can be inferred that increments considerably smaller than 1 ppb will be detectable in depths considerably greater than $1 / 2$ meter. The FLD has an advantage over conventional dye sampling and fluorometer analysis in that it adds the dimension of depth, and the greater mobility of aircraft operations. Turbidity of the water drastically reduces luminescence or even completely blocks the transmission of detectable luminescence to the FLD. Attenuation of light within the water by turbidity and by the dye itself are the major factors to be consideret in interpreting FLD records and in relating luminescence coefficient to lye concentration. An airborne test in an H-19 helicopter established feasibility of operating the FLD from the aircraft power supply, and established that the rotor blades do not visibly affect the monitoring of incident solar radiation. 
 \\ INITIAL TESTS OF USE OF FLD TO MEASURE RHODAMINE WT DYE CONCENTRATION}

\section{General methods}

Tests were conducted in Phoenix, Arizona, during 1968. The FLD was supported on a construction scaffold on casters over a stock tank, also on casters, measuring $2 \mathrm{ft}$. $\times 2 \mathrm{ft}$. $\times 6 \mathrm{ft}$. which was filled to a depth of $1 / 2$ meter (19. 7 inches) with tapwater. The water was allowed to stand for 12 hours or more to allow dissipation of chlorine, since chlorine is known to quench fluorescence of rhodamine dyes. The known volume of the tank, when filled to $1 / 2$ meter, was 474 liters, to which were added equal increments of concentrated rhodamine dye solution in amounts necessary to raise the 'dye concentration of the tank by steps of 1 to $5 \mathrm{ppb}$ to final levels from 40 to 80 parts per billion. Other tests were conducted, as summarized below. The tank was painted flat black on the inside, and was rotated as the sun angle changed in order to assure uniform illumination of the column of liquid sensed by the FLD. The optical sensing unit (Figure 1) was protected from excessive heating in direct rays of the sun by an insulated jacket or by wooden shields. The electronic console and dual channel strip recorder were housed in an air-conditioned van or in an air-conditioned building.

Concentrations of dye in the tank were obtained by two methods. Concentration at a spot location was obtained by withdrawing a small sample for later determination on a laboratory fluorometer by comparison with standard solutions of known concentration. However, the FLD sensed a column of 
liquid $1 / 2$ meter deep, and mixing was seldom completely uniform during conditions of the tests. This resulted simply from the fact that time was not available for adequate mixing because the delay would have introduced additional problems of variation in sun angle, solar intensity, and possibly instrumental drift. Consequently the method used to obtain the best approximation of dye concentrations sensed by the FLD at each moment of a test was to determine the final concentration in the tank after the test was complete, and divide this concentration by the number of increments. This was possible because the increments were known to ba equal, the dye having been measured in advance and stored in separate glass bottles for rapid addition. An alternative method that has been recommended by $F$.A. Kilpatrick (written commin. June 1969) would utilize a circulating pump, to achieve complete mixing in about 1 minut

Relation of luminescence coefficient (rho) to concentration of Rhodamine WT dyc

Tests of ability of the FLD to sense varied concentrations of Rhodamine WT dye in aqueous solution were conducted as follows, all in depths of $1 / 2$ meter: 1) Tests with dye increments averaging about 5 parts per billion. The most successful of these was conducted on June 17, 1968, from 9 to 10 am and the resulting strip-chart published (Hemphill, 1968)。 2) Tests with dye increments averaging approximately 4 parts per billion.

The most successful of these was conducted on November 1 , from 1:20 to $1: 36 \mathrm{pm}$.

In 12 successive increments averaging 3.7 parts per billion, the sensitivity of the FLD was such that $\underline{\text { rho }}$ averaged 0.06 per $1 \mathrm{ppb}$.

3) Tests with dye increments averaging approximately 3 parts per billion. The most successful of these was conducted on October 29, from 11:14 to 11:50 am. In 17 successive increments averaging 3.2 parts per billion, 
the sensitivity of the FLD was such that rho averaged 0.025 per $1 \mathrm{ppb}$.

4) Tests with dye increments averaging less than 2 parts per billion.

The most successful of these was conducted on November 2, from

11:23 to $11: 52 \mathrm{am}$. In 25 successive increments averaging 1.3 parts per billion, the sensitivity of the FLD was such that rho averaged 0.053 per $1 \mathrm{ppb}$.

Conclusions resulting from the above tests are:

1) Detectable increments of dye concentration are partly a function of instrumental sensitivity at the time of the test and partly a function of ability to differentiate small steps in the recorded values of $\underline{\text { rho. The latter }}$ is partly a function of the signal to noise ratio, which is reflected in the amount of background chatter recorded by the pen.

2) Smallest detectable dye concentration increments in $1 / 2$ meter depths were approximately 1 part per billion.

3) Smallest detectable steps on the recorder chart were equivalent to a rho increment ranging from about 0.025 to 0.05 , depending chiefly on the background noise.

4) The smallest detectable steps on the recorder chart can better be expressed in terms of dye concentration, which must have been roughly proportional to luminescence signal. In these terms, the detectable increment on most sunny days could be considered roughly equivalent to the luminescence from $1 \mathrm{ppb}$ of dye in $1 / 2$ meter depth. 


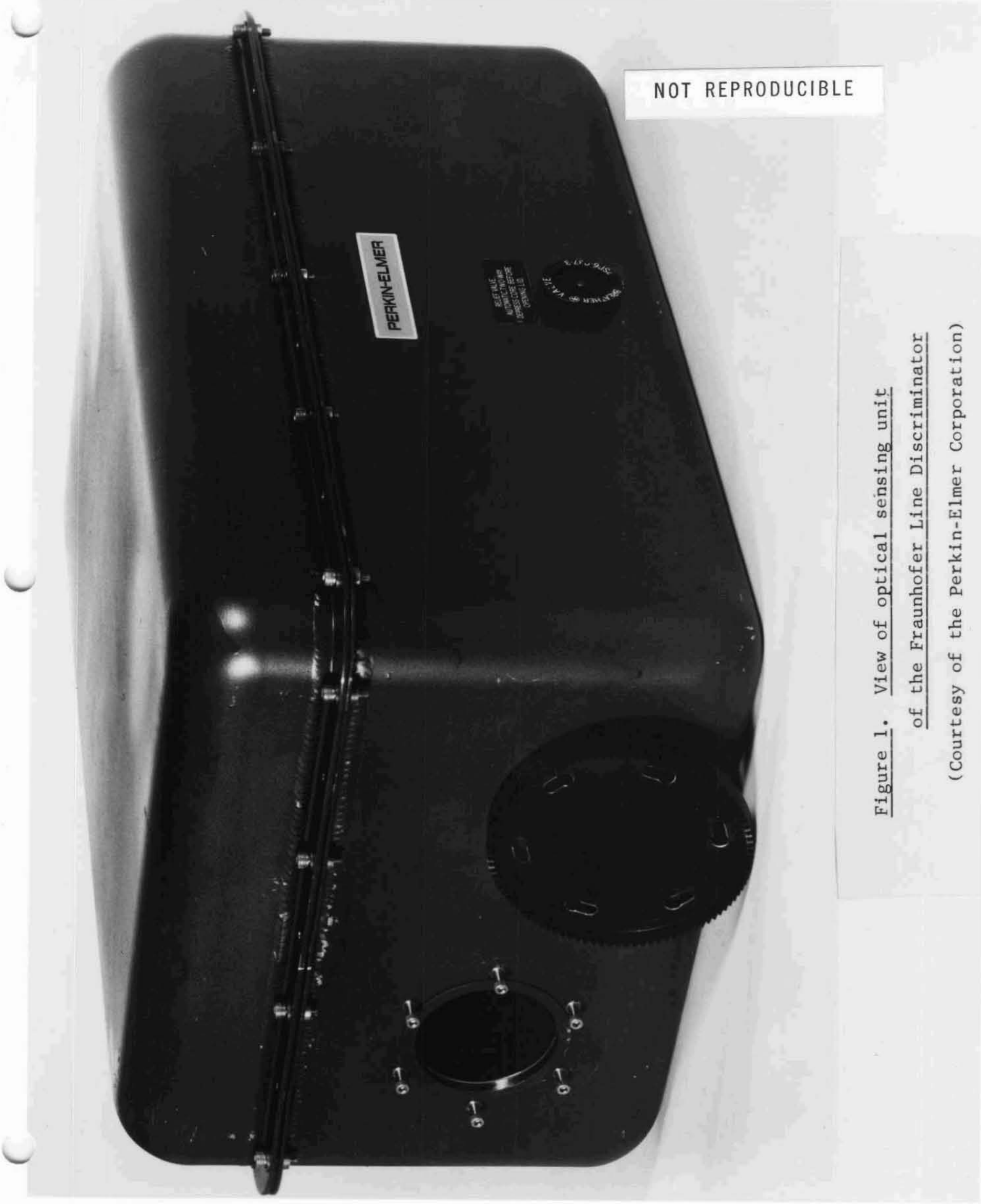


Eigure 2. Strip-chart from dye concentration test of FLD on October 29, showing 17 successive increments averaging 3.2 parts per billion of Rhodamine WT dye

Explanation:

Depth of solution: $\frac{1}{2}$ meter ( 19.7 inches)

Dye concentration: determined from surface samples; better accuracy for total column sensed by FLD is obtained by dividing final concentration by number of increments Note that noise level increases as signal level increases A slight down-trend from strict linearity for the higher concentrations results from greater attenuation of light

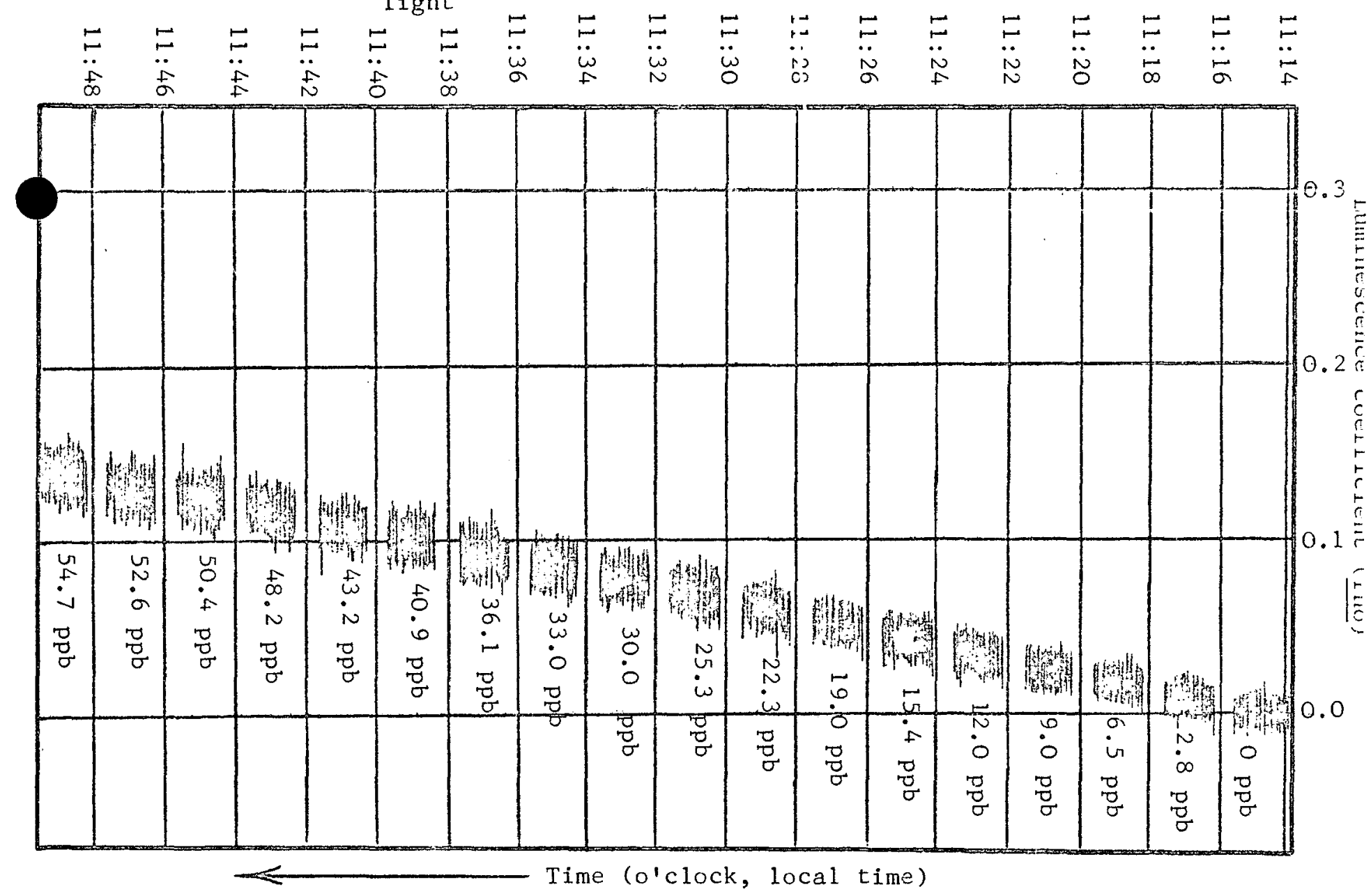


5) Extrapolating to greater depths, it can be inferred that increments considerably smaller than 1 ppb would be detectable in depths considerably greater than $1 / 2$ meter.

The strip-recorder chart from the dye concentration test of October 29 is shown on Figure 2. In this test the recorder pen was lifted while each dye increment was added and while the tank was stirred.

When tho values from Figure 2 are plotted aginst dye concentrations measured by fluorometer the curve shown by dashed line in Figure 3 results. This curve is roughly representative of the variations in surface concentration at one point, while the total column sensed by the FLD is better represented by the solid line on Figure 3 . This was obtained by assuming that all increments were equal, as they were known to be if averaged over the entire tank, because added quantities of dye were exactly equal. It is assumed that dispersal was unequal because insufficient time was allowed for complete mixing. Therefore, the actual column sensed by the FLD could not have been exactly as shown by the solid line.

However, it can be seen that rho values obtained from Figure 2 must also be an approximation, due to the noise level. The method of obtaining these values is to visually obtain the average level by use of a transparent template with a horizontal ruled line. As a result both the rho levels and the dye concentrations shown by the solid curve on Figure 3 are based on a method that eliminates small irregularities and the result is a curve that emphasizes the trend and is particularly useful in theoretical analysis of the rlated factors. Curves of this type assisted in derivation of the theoretical formulas 


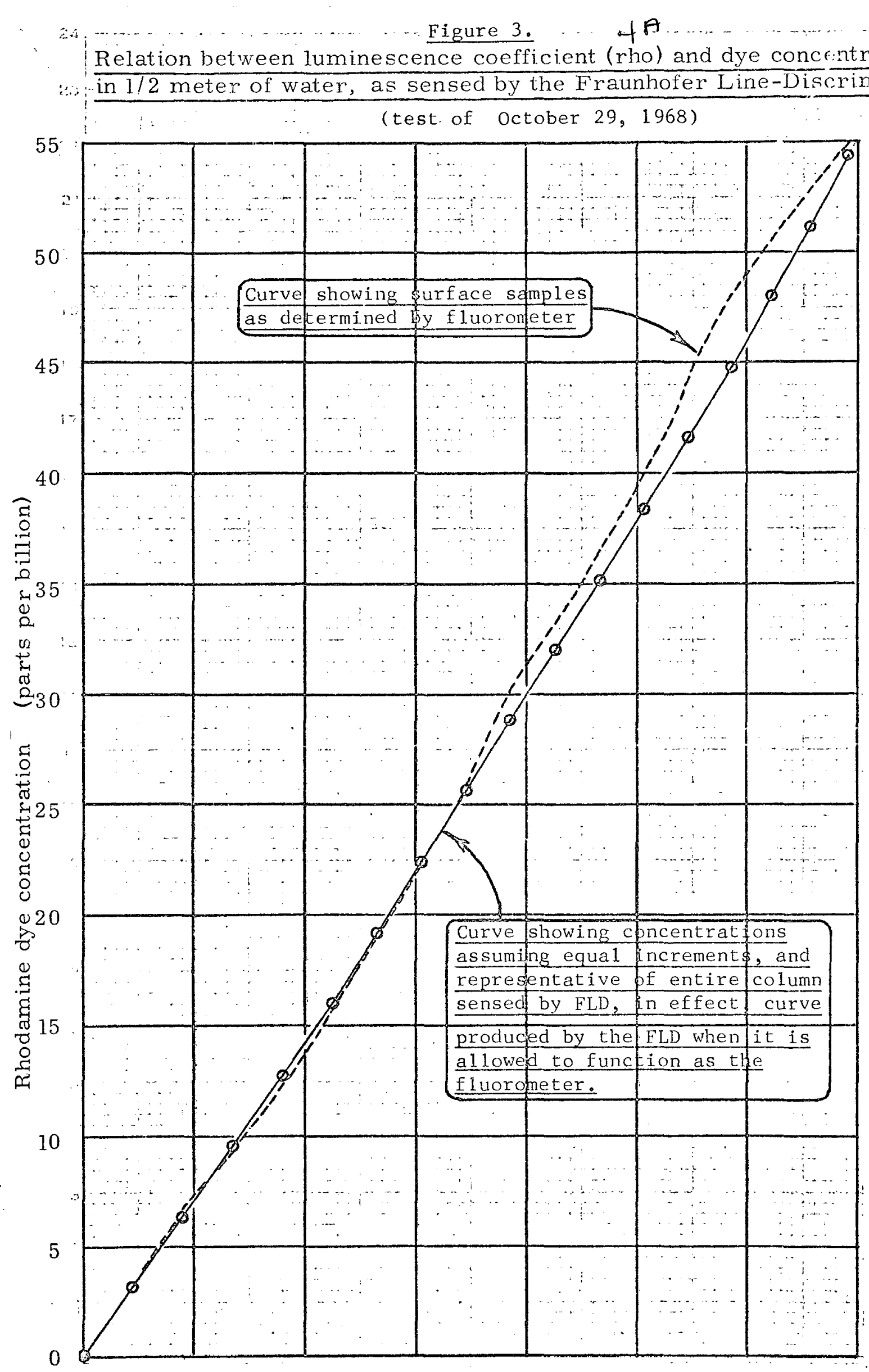

$\begin{array}{llllllllllllllllllll}0 & 0.1 & 0.2 & 0.3 & 0.4 & 0.5 & 0.6 & 0.7 & 0.8 & 0.9 & 1.0 & 1.1 & 1.2 & 1.3 & 1.4\end{array}$ Luminescence coefficient (rho) 
described in foregoing reports (Stoertz, G.E., 1969 a and b). Another view of the smooth curve is that it represent: the use of the FLD as the fluorometer. This suggests that when the FID is viewed as a fluorometer, it adds the dimension of depth to the measurement, in comparison to ordinary fluorometer samples which represent virtually a single point of the water body. This can be an advantage, if FID records can be adequately interpreted, but if not, the dimension of depth would add an element of confusion and indeterminacy.

Relation of Iuminescence coefficient to depth of Rhodamine WT dye solution

Tests of viriation of detectable luminescence with depth of liquid sensed by the FID were conducted in six ways, with varying success, each designed to isolate different components of total attenuation, or to combine them in different ways, as follows:

I) Tests by varying the depth of aye colum sensed by the FID while eliminating the effect of absorption of incident light. The most successful of these was conducted on October 29 from 1:35 pm to 1:56 pin. An empty vertical cylinder of acrylic resin (Iucite) that only slightly exceeded the field-of-view of the FLD was filled by a Rhodamine WI dye solution in 20 depth increments, from 0 to 23 inches while being viewed by the FID.

2) Similar tests, while including the effect of absorption of incident light were moderately successful on October 28 , from $2: 38 \mathrm{pm}$ to $2: 54 \mathrm{pm}$. An empty vertical lucite cylinder surrounded by a tank of Rhodamine WI dye solution ( $71 \mathrm{ppb}$ ) was filled with an identical solution. in 17 depth increments, from 0 to 18.5 inches, while being viewed by the FID.

3) Tests by varying the depth of dye column sensed by the FID, while 
including the effect of absorption of incident light, and without introducing a lucite barrier, were successful on october 27, from 11:48 am to 12:07 pm. An opaque flat-black plate was raised through a tank of . dye beneath the FID in 7 depth increments, from 19 to 0 inches. This had the effect of raising the bottom of the tank, differing from the previous test in that the path-length of incident light was minimum when the depth was minimum, while in the lucite cylinder test the reverse was true.

4) Tests of a similar nature, by varying the effective bottom level without actuallj introducing an obstacle, were successful on November 2, from 12:4I to $15: 56 \mathrm{pm}$. An opaque shield that completely blocked sunlight from a tank of Rhodamine WT dye being viewed by the FID was lowered in 12 increments until the entire column was fully illuminated.

5) Tests by varying the effective depth of the colum illuminated, without varying the effective attenuation coefficient for emitted light, were moderately successful on November 1 from $2: 06$ to $2: 24 \mathrm{pm}$. An opaque shield that completely blocked sunlight from a column of Rhodamine WI dye being viewed by the FID was raised in 12 increments until nearly the entire column was fully illuminated. Consequently attenuation of emitted. light by the full column was in effect throughout the test.

6) The attenuation of light by water alone was isolated by varying the depth of a submerged container of Rhodamine WI dye being viewed by the FID. This test was moderately successful on November 2, from 11:07 to 11:12. A lucite cylinder in a horizontal position filled with dye solution was used for this test. 
Quantitative conclusions that could be drawn from the above tests would relate almost entirely to the attenuation coefficients of rhodamine dye solutions, and are inconclusive because instrumental sensitivity was not monitored by means of a standard.

General conclusions were:

1) Attenuation coefficients of incident light by rhodamine dye solutions are the major factor to be considered in interpreting FLD records, these having a greater potential effect on rho values than variations resulting from intrinsic luminescence itself. In effect, the illumination of the dye column sensed by the FLD is more important than how much dye is in the column, although the two are obviously inter-related.

2) Analysis of certain depth tests, in particular the test of October 27 , permitted isolation of the effect of attenuation from that of sun angle alone.

3) The attenuation of emitted light by the dye column is extremely small by comparison with the attenuation of incident light.

4) In general the depth tests indicated the approximate interrelationships among the factors necessary to relate rho to dye concentration.

The procedure used in the depth test of November $l$ is shown on Figure 4. In this test an opaque hollow box, open at both ends, was raised and lowered around the column of dye viewed by the FLD. Since the attenuation coefficient for emitted light was unchanged during the test, the departure from a straight line can be attributed entirely to attenuation of incident light. The curvature shows the increasing attenuation with increasing depth, due to the longer path-length of the incident light, but actual values of rho are in error because 
dye column illuminated by sunlight, as sensed by the FLD (depth test, Nov. 1)

(shows isolated effect of increasing attenuation $\therefore=$ cf incident light with increasing depth;'.

(positions of opaque hollow box with respect

$\therefore$ to water surface, field of view, and sun angle

$\because$ are illustrated in sketch at right)

20

19

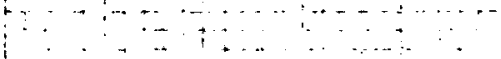

Metal shield

18

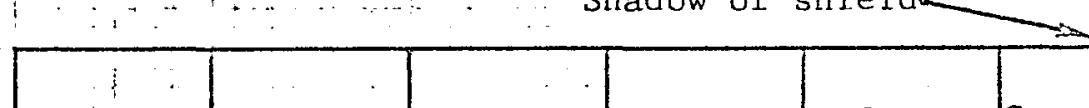

17

(

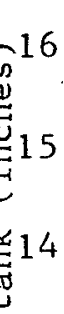

虫13

O

$\stackrel{+}{\circ} 12$

$\rightarrow$

$\sum_{0}^{\infty} 11$

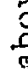

(10

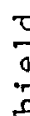

Lower edge of thield 18.3 in. aboye floor -3
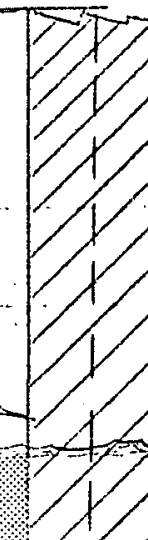

Shadow of shieldan 
the zero level was apparently of $i$ the chart, resulting in an erroneous zero value at 3.9 inches from the bottom (i.e., at an effective level 2.6 inches from the bottom).

By comparison, the isolated effect of changes in attenuation of emitted light with increasing depth are shown by Figure 5. This is a portion of the test of October 29, made by filling the vertical cylinder with a uniform zolution of Rhodamine WI dye in equal depth increments. The cylinder completely encompassed the field of view, but very little else, and was surrounded by air. The very nearly straight-line relationship between rho values and depth indicate trat only an insignificant amount of attenuation could be attributable to that of emitted light, by the dye itself.

The most useful and unambiguous data are obtained from tests such as the opaque-plate test of October 27. The curve of luminescence coefficient vso depth of dye column sensed by FLI), while the plate was raised through a $I / 2$ meter column beneath the iristrument, is shown on Figure 6. It should be noted that the vertical axis represents depths, so that the lower edge represents the water surface. The dashed line represents the approximate relation that would ideally have occurred. if attenuation of light were not a factor, and the departure of the two lines is a measure of the cumulative attenuation with depth.

Relation of luminescence coefficjent to angle of the sun's rays Sun angles measured during the tank tests varied from about $20^{\circ}$ to $45^{\circ}$ above the horizon, approximate curves being shown on Figure 7 . The easiest 

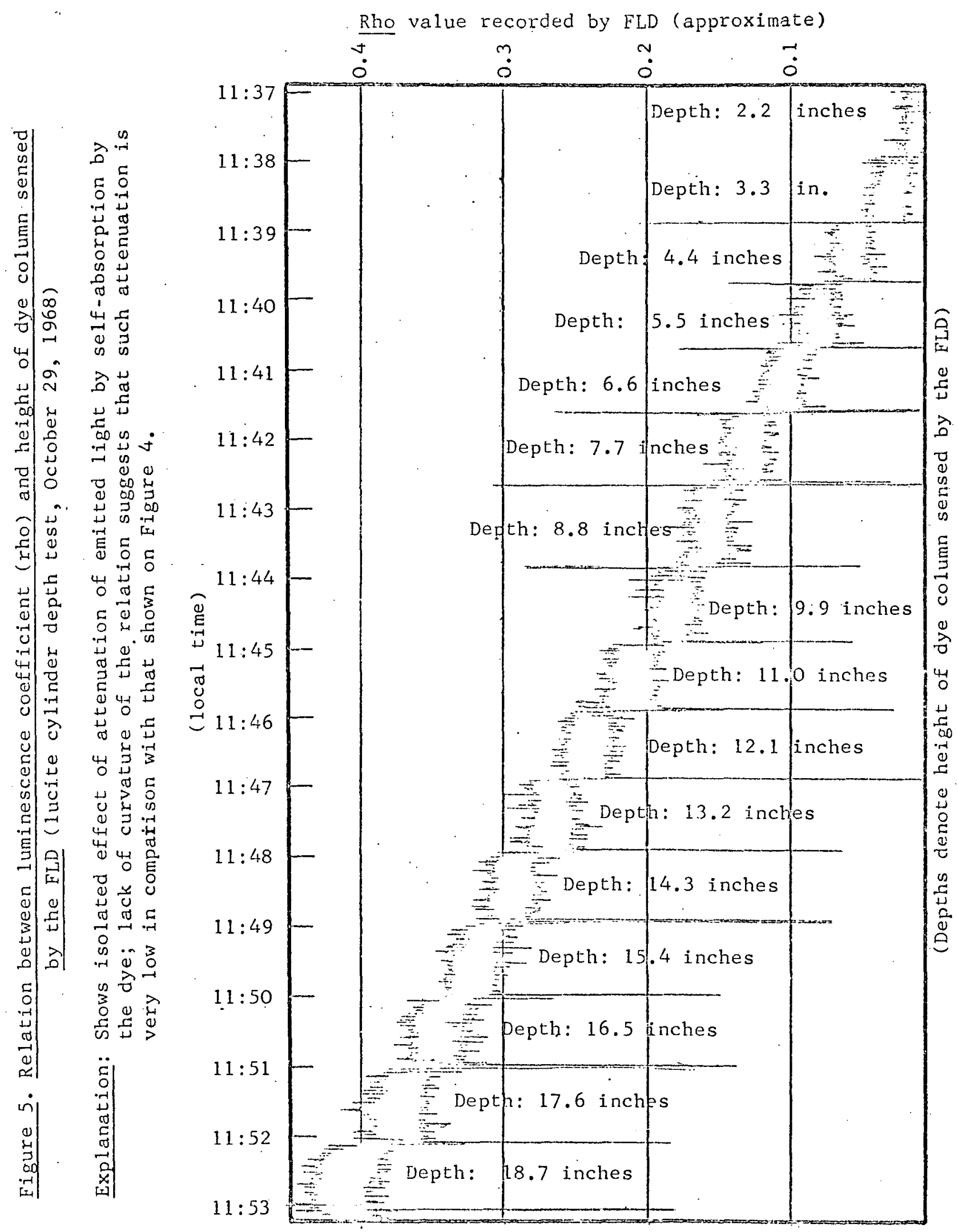
FIGURE 6 .

RELATION BETWEEN LUMT NESCENCE COEFEICIENT (RHO)

AND DEPTH OF DYE SOLUTION IN THE RANGE_EROM

1 INCH TO I INCHES, AS SENSED BY THE

FRAUNHOEER LINE-DISCRIMINATOR (F.L,D.)

(based on opaque-plate depth test of oct. 27, 1968)

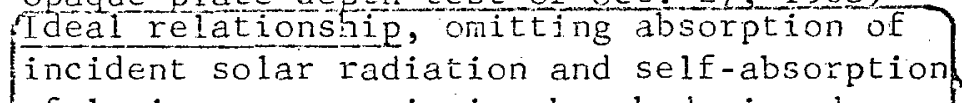

of luminescence emission by rhodamine dye

solution in the tank.

Observed relationship, as measured by the F.L.D)

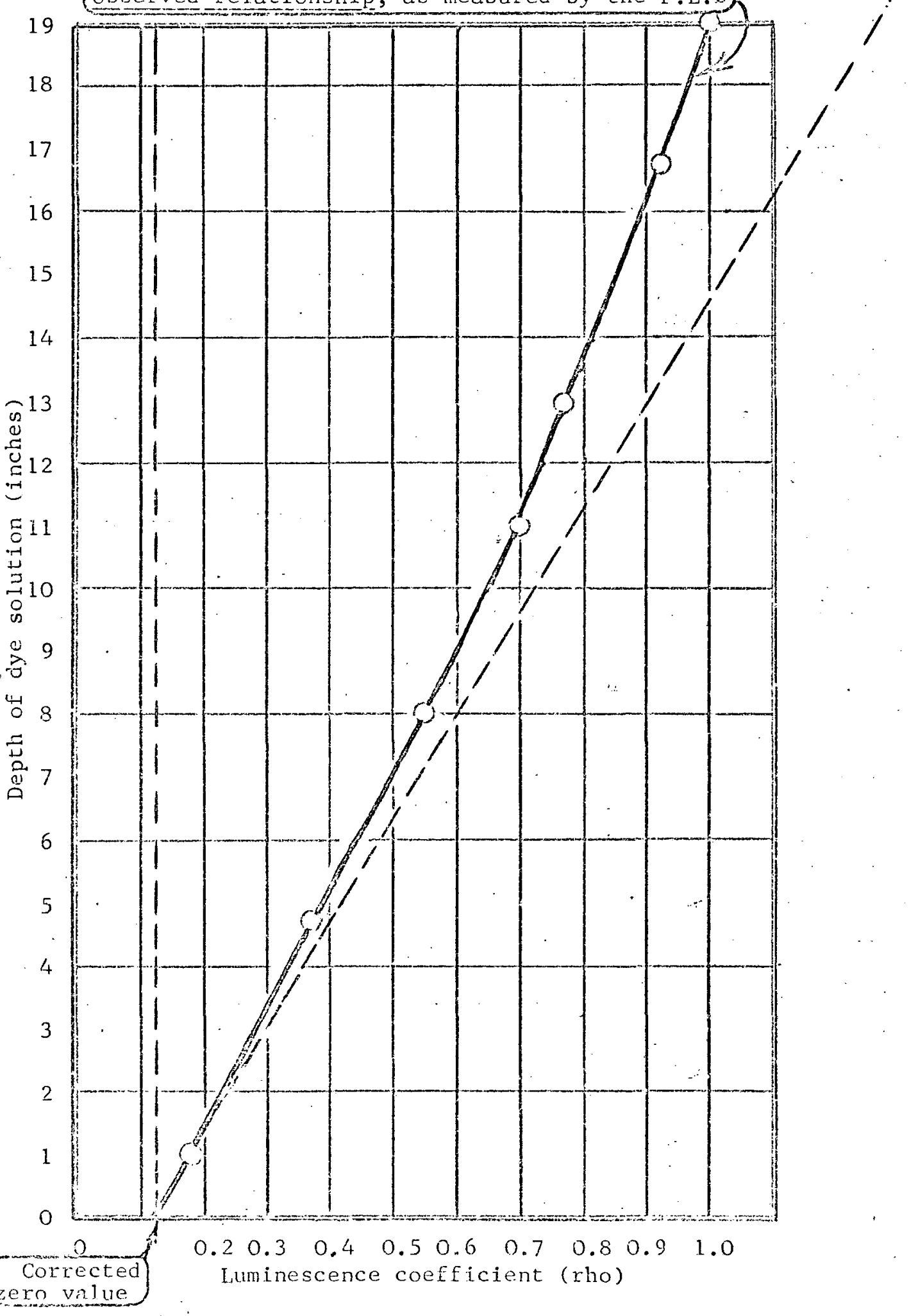


Figure 7. Sun angles during FLD tests and relation to reflectance from calm water

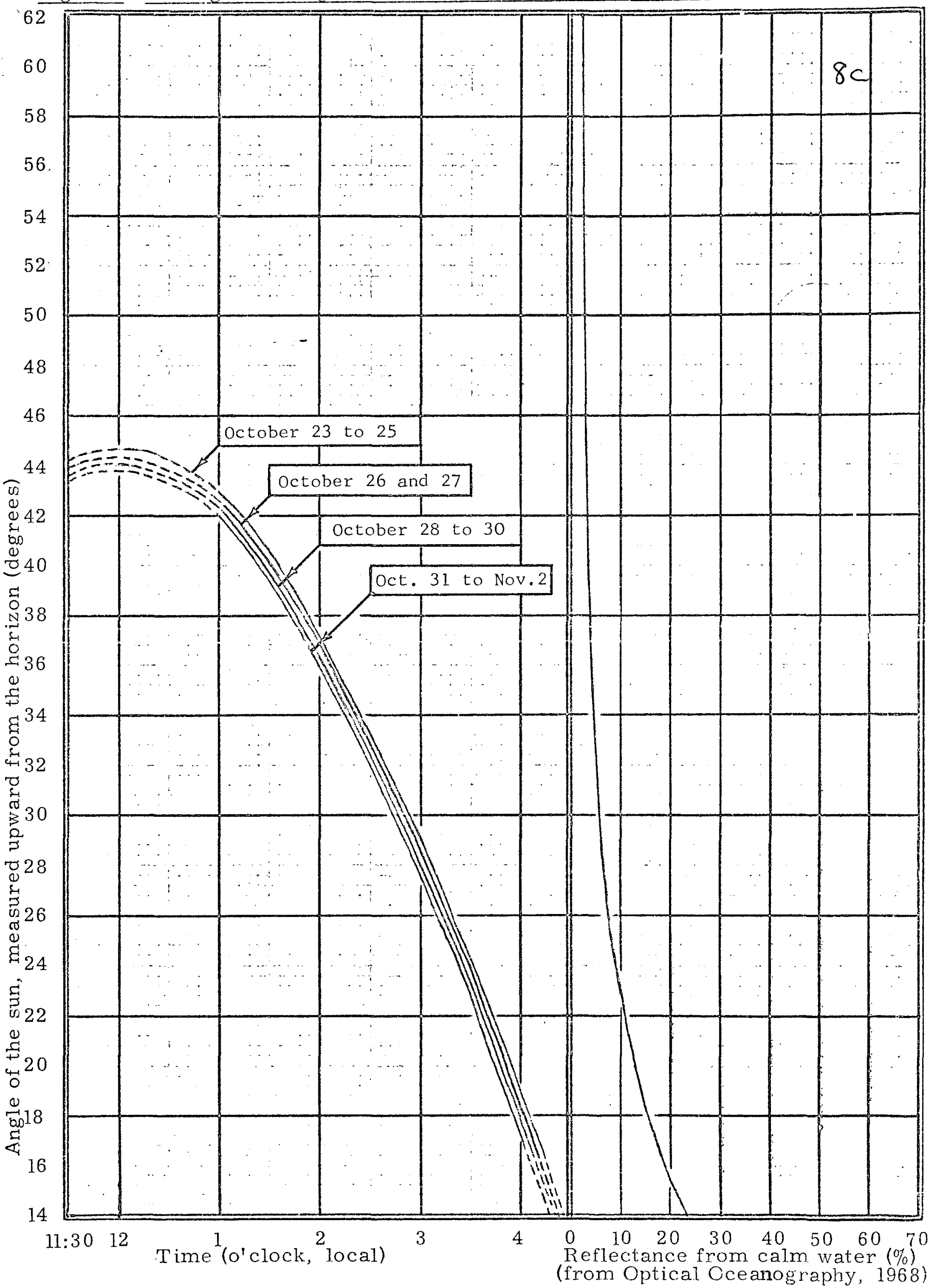


method is to use measured angles for interpretation of tests at a single location, or to use the nautjcal almanacs for angles during airborne. tests, where it is inconvenient to measure the angles. It is sufficient to know the sun angle within an accuracy of about \pm 10 for angles over $25^{\circ}$, within an accuracy of about $\pm 1 / 2^{\circ}$ for angles between $15^{\circ}$ and $25^{\circ}$, and as close as practicable for lower sun angles. The graph of reflectance vs. sun angle shown on Figure 7 makes it apparent why accurecy is increasingly important below $25^{\circ}$.

Since sun angle is a primary factor in interpreting FID records it can be seen that the optimum time for sensing with the FLD will be during the 2-hour period centering at the time when the sun is highest. During this 2-hour period it will be possible to use a simplified computation with a single sun angle.

It might appear at first consideration that the period of optimum sensing (for ease of computation) will increase as the season progresses from the sumer solstice, because the sun angle curve will become flatter, allowing a longer period of nearly constant angle. This is not the case, since the flattening of the sun-angle curve will be compensated by an increase in signigicance of sun angle as a determining factor on luminescence of dye solutions. This should mean that at any given latitude the 2-hour period around midday will be optimum for sensing at any time of the year.

Regarding seasonality, the theoretical formulas of FLD function indicate that greatest sensitivity will be attained at the highest sun angles, and therefore at any given latitude the summer solstice (June 2l) is optimum and winter solstice (December 21) is worst. The same consideration applies to latitude. Best results will be achieved at lower latitudes, or at least at latitudes having highest midday sun angles. 
Relation of luminescence coefficient to temperature of Rinodamine WI

dye solutions

Tests of the variation of detectiable luminescence with temperature of solutions were conducted, as follows:

I) A test by cooling the 474 -liter tank from $23^{\circ} \mathrm{C}$ to $16^{\circ} \mathrm{C}$ by addition of 1001b. of ice was conducted on october 27 from 1:25 to $3: 30 \mathrm{pm}$. The resulting data are summarized on Figure 8, but are inconclusive because temperature was measured at a point about 4 inches below the surface and subsurface layers must have been appreciably cooler. In addition, warming of surface layers began at about $2: 20 \mathrm{pm}$ (shown by lower graph) while subsurface cooling beneath the FTD appears to have continued until about 2:45 pm when corrected Iuminescence coefficients began to decline as shown on upper graph. Use of a, pump agitator in future tests of this type should eliminate themal layering.

2) Tests of temperature-dependence of Rhodamine WI dye Iuminescence were made with a laboratory fluorometer in the range from $9^{\circ} \mathrm{C}$ to $18^{\circ} \mathrm{C}$ and from $25^{\circ} \mathrm{C}$ to $34^{\circ} \mathrm{C}$. Changes in dial reading were recorded as samples warmed up in the sample compartment, and in other tests changes in dial reading were noted as samples warmed in a water bath.

Results were generally less satisfactory and less consistent that published data (Wilson, J.F., Jr., 1967, written commun.) on temperature dependence of Rhodamine WI dye. Consequently the temperature correction coefficient will be based entirely on previous data. Experiments with the FID served to corroborate the fact that the temperature factor is significant and should not be overlooked. The decrease in Iuminescence of rhodamine $B$ is reported to be 2.3 percent per degree centigrade (Watt, 1965; Markle and others, written commun., Nov. 26, 1968) over the range from $12^{\circ} \mathrm{C}$ to at least $28^{\circ} \mathrm{C}$. 
to a single layer or averaged with other temperatures to obtain a single correction coefficient. In this case the average should ideally be weighted to correspond to average depth from which Irminescence emanates.

\section{Relation of luminescence coefficient to turbidity of solution}

Tests of the relation between turbidity of Rhodamine WI dye solutions and their Iuminescence were conducted, as follows:

1) An undisturbed cylinder of turbid dye solution (70 ppb) 1/2 meter deep was found to have no detectable luminescence after settling 24 hours. However turbidity was excessively high, created by addition of fine playa clay and. silt from Mud Lake, Nevada, resultiig in a solution comparable to an exceptionally mody river, even after 2.4 hours. The grain size and settling rate of an identical control solidion were tested by hydrometer under fdentical temperature and illumiration.

2) The supernatent fluid from the above cylinders was tested by fluorometer to determine whether the luminescence was mechanically blocked by scattering and attenuation by the suspended sediment or whether the Iuminescence was permanently quenched by adsorption or chemical reaction. The uppermost 1 to $2 \mathrm{~mm}$ of clear fluid, after settling for 48 hours, showed nearly complete restoration of detectable luminescence, suggesting that mechanical blocking of the incident light was the predominant effect.

The above conclusion is highly tentative, since much more work is needed to define the actual relation between turbidity and luminescence, particularly in terms of attenuation coefficients or some other measurable parameter. In addition, investigation of adsorption of Rhodamine WT dye on suspended sediment of various grain sizes is needed. 
FIGURE 8.

REI.ATION BETWEEN LUMINESCENCE COEFFICIENT (RHO) AND TEMPERATURE

I: $\frac{1}{2}$ METER OI RHODAMINE DYE SOLUTION, AS SENSED BY THE

FRAUNHOFER LINE-DISCRIMINATOR (H.L.D.)

(temperature test of October 27, 1968)

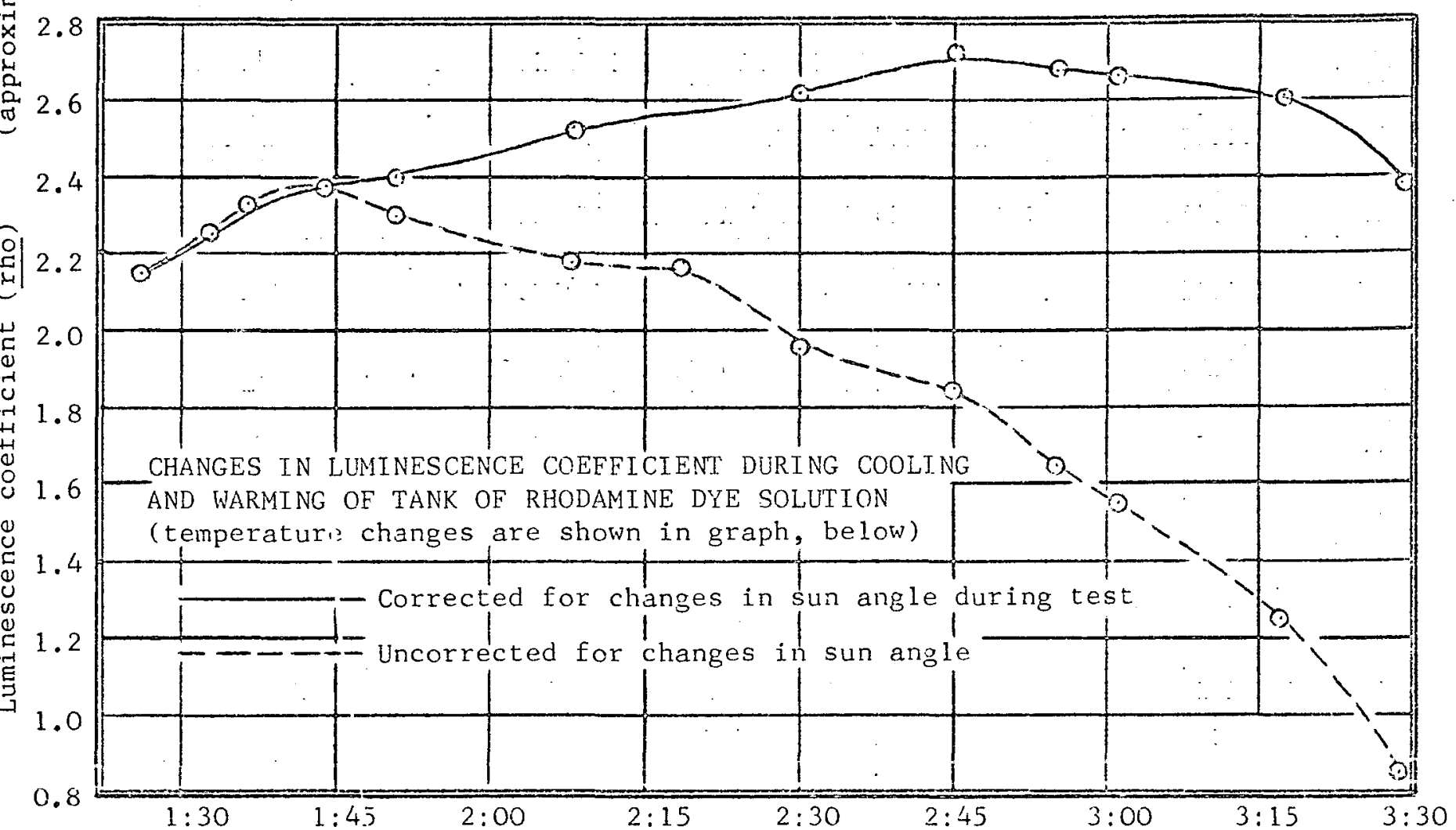

(Time)

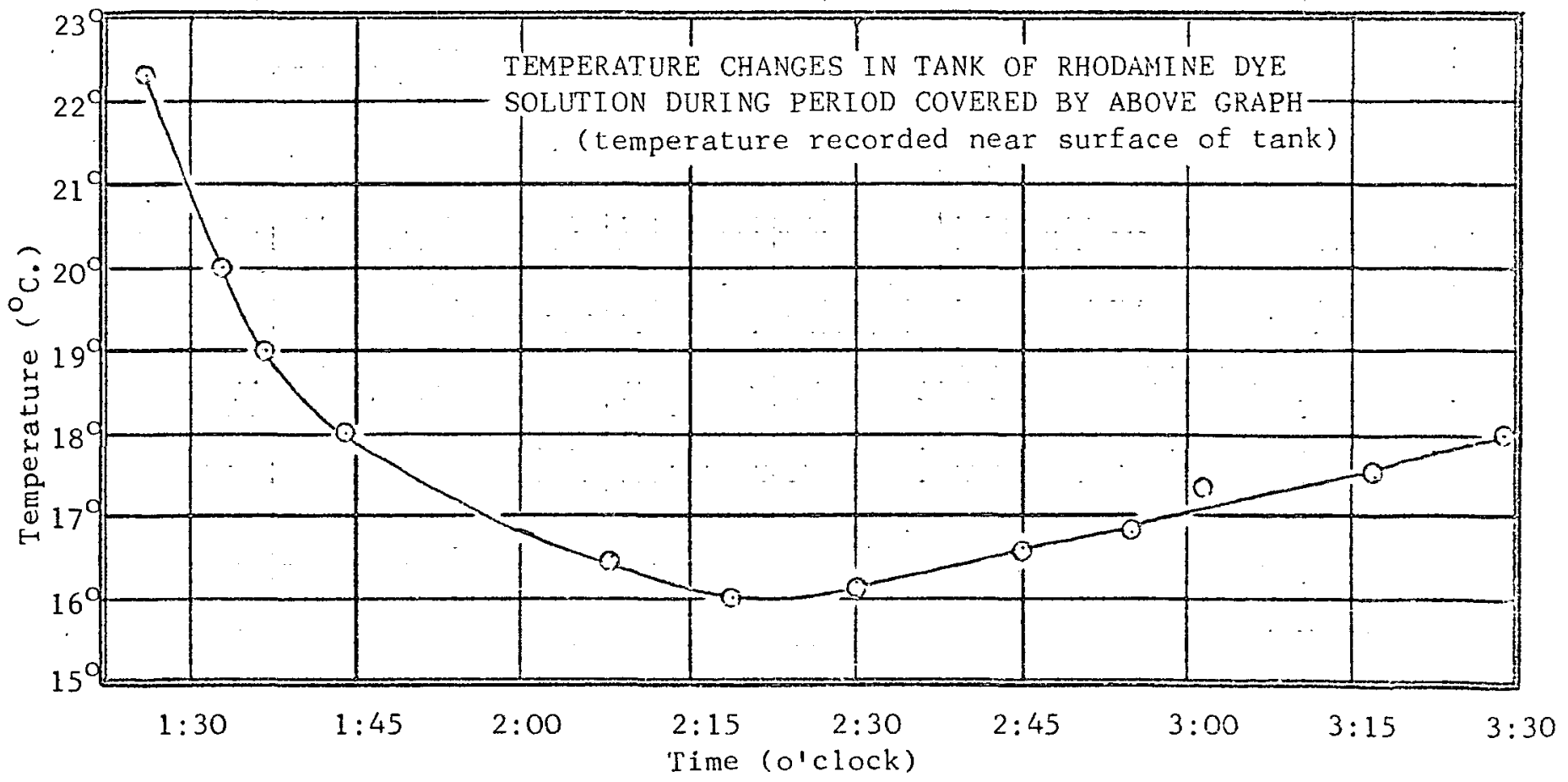


Table 1. Percentage loss of fluorescence caused by adsorption of Rhodamine WT dye on sand and silt particles (from Watt, 1965)

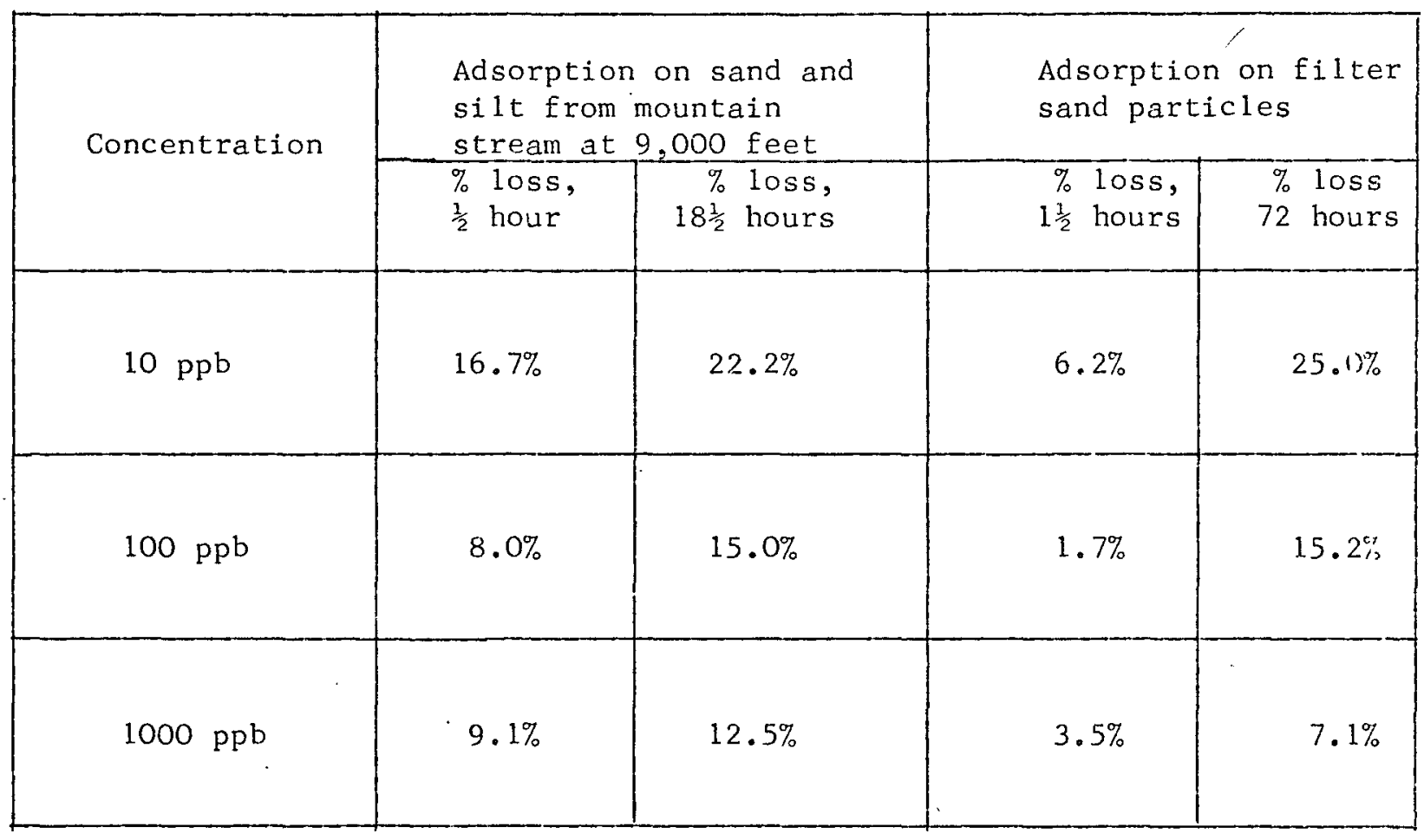


A comparable finding has been noted by Wilson (1967, written)

in discussing ise of flow-through fluorometry:

"In streams with very heavy suspended loads, the background count from scattered light may totally mask fluorescence. Under such conditions, the flow-through method may not be used; grab sampling will allow settling of the suspended material."

Loss of Iluorescence due to adsorption of fluorescent dyes on suspended sediment or on bottom sediment has been investigated by Watt (1965). His results show a surprisingly high percentage loss, not only of rhom damine B but also of Rhodamine WT. His results, partially summarized on Table 1 , indicate a loss of $16.7 \%$ of fluorescence from Rhodamine WT solutions of 10 ppb concentration after only $1 / 2$ hour on sand and silt, while the loss was $6.2 \%$ after $1-1 / 2$ hours on filter sand. The loss for solutions of $100 \mathrm{ppb}$ concentration was $8.0 \%$ on sand and silt. Projecting these results to low concentrations on the order of 1 ppb or less such as are anticipated in operational dye studies with the FW, and projecting them to the very fine-grained clay and silt-sized particles likely to be suspended in coastal or estuarine waters, it appears probable that failure to account for adsorption losses might be even more serious than failure to account for sun angle.

It would be valuable to further investigate such adsorption losses, particularly in conditions that will approximate natural conditions during operational studies. The most valuable data would be in the concentration range from 0 to 10 parts per billion, in the time range from 0 to 24 hours, in the grain-size range of clay and silt, and in the turbidity range represented by attenuation coefficients from $0.10 \mathrm{~m}^{-1}$ to $0.50 \mathrm{~m}^{-1}$. 
Watt's data are also of iriverest in that they indicate a significantly lower adsorption loss for Pontacyl Pink B than for Rhodamine WT, in spite of the fact that the latter is reputed to have less tendency toward adsoprtive loss than the former (Wilson, J.F., Jr., 1967, written commun.). This may be the result of the particular conditions of tests, however, including the particular soils used, and serves to emphasize the need for more definitive studies relating to the function of the FLD.

When better data are available on adsorption loss in relation to FLD function, it will probably be advisable to combine such losses with losses caused by exposure to light, photo-cr emical deterioration, and other causes. It is apparent that loss in Iuminescence of the dye with time will occur. These could be combined in a coefficient of luminescence loss, expressed in percent per hour.

Other results of testing of the FID

Additional tests and observations that have been made on the funcm tion of the FLD are enumerated below:

1) An apparent correlation was found between length of the lucite tube beneath the light collector and noise in the record of luminescence coefficient (rho). A longer tube seems to produce less background noise, within limits, but these limits were not determined because the effect was noticed only after tests were complete. The tube length was changed only once, on October 10 at about 2:30 pm (Figure 9). Further testing of this and several similar factors related to the light collector is of high priority.

2) The relation between reflectance of target materials and recorded values 
Eigure 9. Apparent relation between length of $\frac{\text { FLD light-collector tube and noise }}{\text { in record of luminescence coefficient }}$

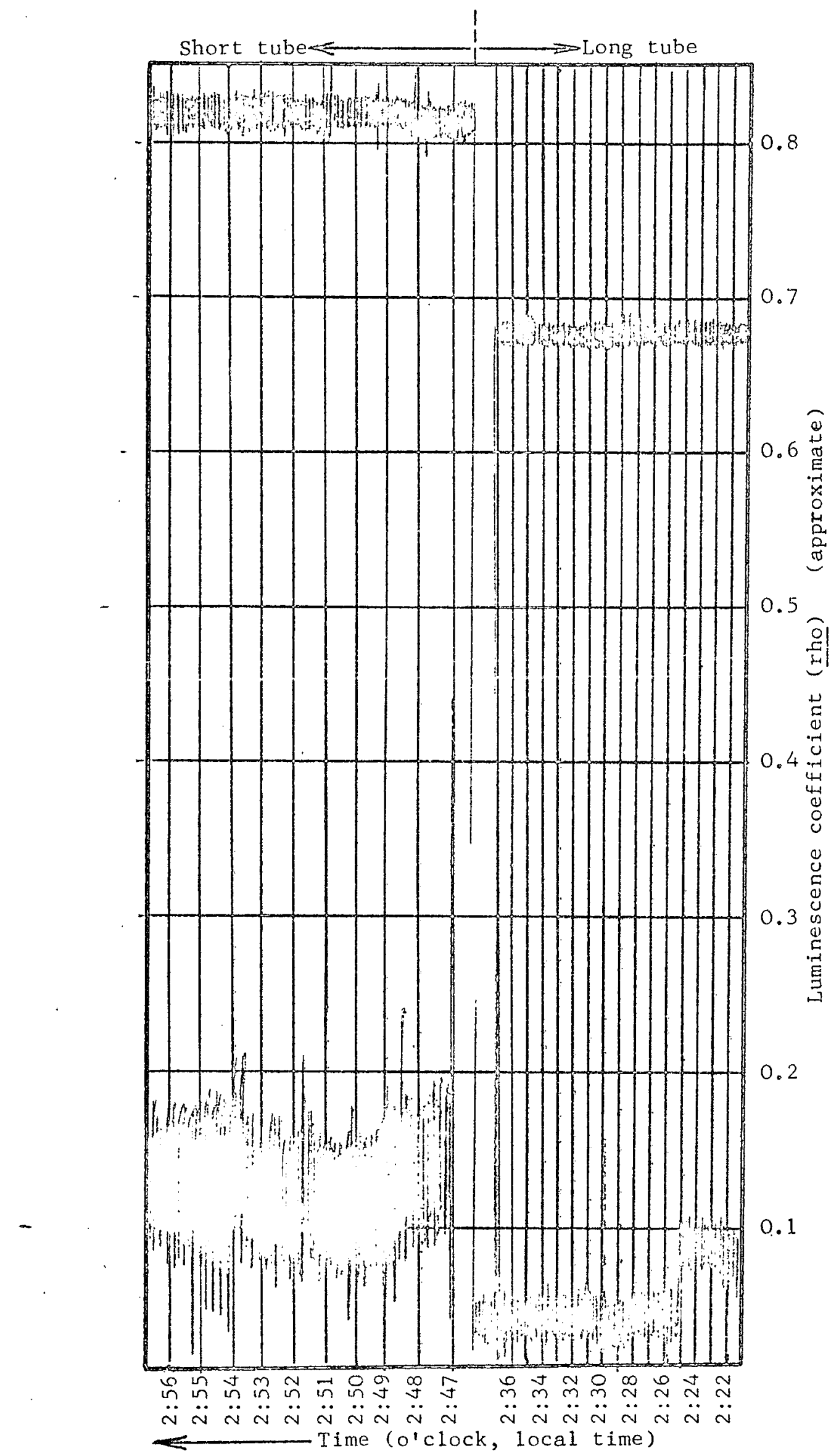


Figure 10. Spurious "luminescence coefficients"

recorded by FLD from non-luminescent

reflective materials, showing dependence

of signal on orientation of the material

(reflectivity test of November 2, 1968)

Explanation: Sensitivity to reflectivity was observed only when the latter exceeded some

critical limit. This limit is estimated

to be a function of adjustment of the

instrument. Even when only moderately

well adjusted (more than one week after

tuning, and after approx. $30 \mathrm{hrs}$. of use)

the critical limit is estimated to exceed

the level of reflectance likely to occur

during viewing of open water, vertically.

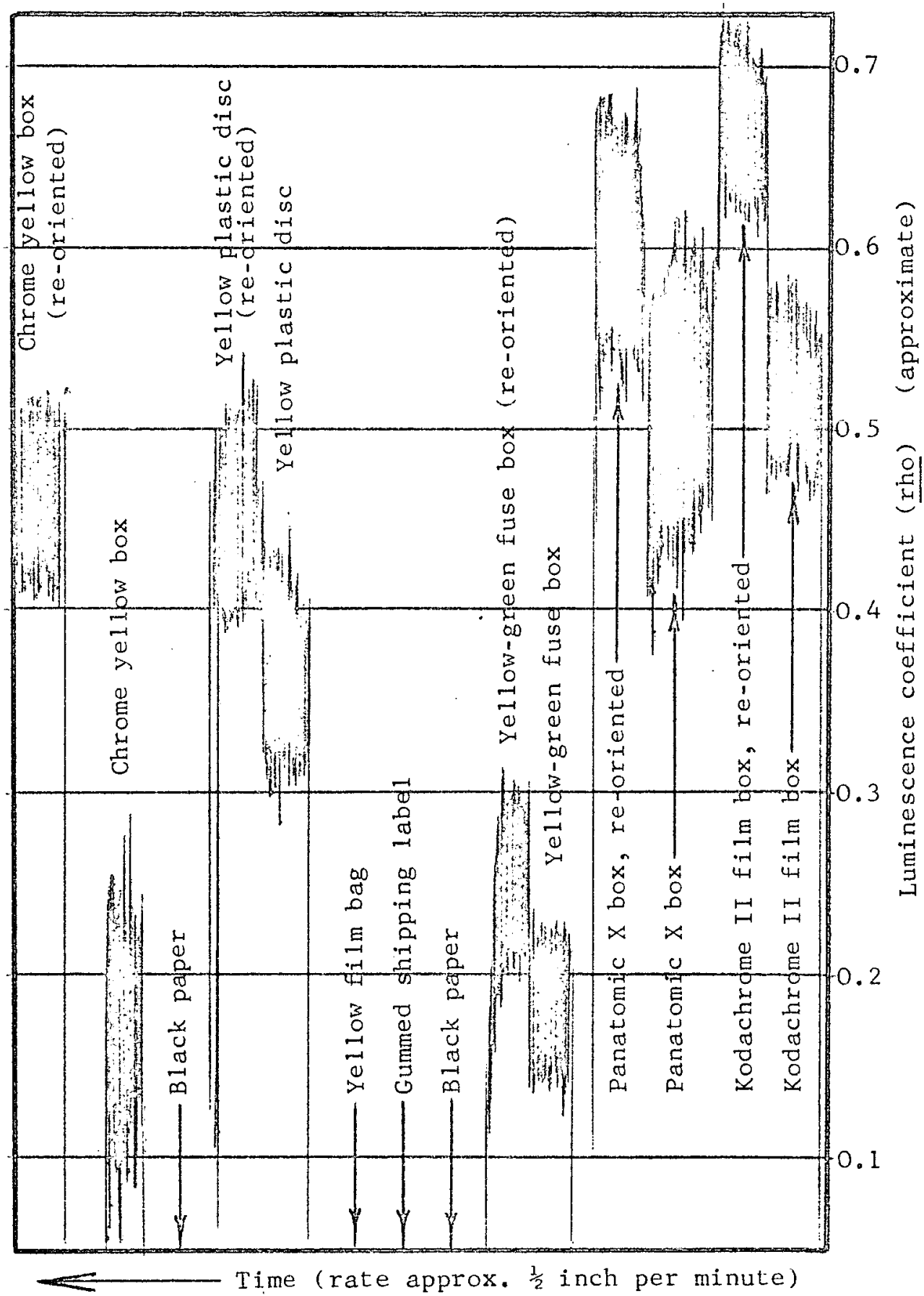


of rho was briefly investigated on November 2 from 1:07 to 1:23 p.m。 When reflectivity exceeds some critical limit the instrument apparently cannot cope with the signaI and records a Iuminescence coefficient (Figure 10)。 This critical limit was not defined, but is thought likely to vary with perfection of electronic adjustment or tuning. Agitation of a tank of water being viewed by the FID in the sunlight, producing small waves, failed to produce any spurious Iuminescence coefficient。 Therefore it is concluded that when the instmument is reasonably well adjusted this sensitivity to reflectivity is not likely to be a problem over water.

3) Tests of the FID over tanks of Rhodamine WI dye in early october revealed occasional spurious shifts in recorded values of Iuminescence coefficient. An interchange of amplifiers indicated that the shift was attributable largely to a defective amplifier ( $\log$ and antilog transducer) which was replaced. Some continued shifts of the same type were noted subsequentIy, but the shifts are generally obvious and can be compensated by using a standard target to find the new effective zero level.

4) A brief airborne test of the FID was conducted in an $\mathrm{H}-19$ ( $\mathrm{S}-55)$ helicopter, with the recorder monitoring the $B / A$ ratio. The test established compatibility with the aircraft power supply, using a I15-volt generator, and established that rotor blades do not effect the record. It should be noted that maximun power input for operation of the FLD with all heaters in use is approximately 500 watts, of which 300 watts are for the heating. Required power is 115 volts, $60 \mathrm{HZ}$. 
5) The relation of atmospheric phenomena such as clouds, smoke and haze to the recorded values of luminescence coefficient were observed. Dependence of rho on the presence of clouds between the sun and the instrument were noted particularly on the records of October 26 from $2: 32 \mathrm{pm}$ to $3: 12 \mathrm{pm}$, on October 31 from 11:40 am to 11:48 am, and on November 2 between 11:23 am and 12:08 pm. The record of October 31 (Figure 11) shows a steady rho value between 11:30 and 11:40, while the FLD viewed a container of Rhodamine WT dye solution. The prominent dip between $11: 40$ and 11:48 was caused by the passage of heavy cirrus clouds across the sun. The tentative conclusion from this and similar observations is that the dependence is reated to the variation in intensity of solar radiation rather than to its composition. A polarization effect related to selective reflection by ice crystals of the cirrus clouds and to the orientation of the light collector seems unlikely but cannot be ruled out entirely.

Two alternative explanations deserve further consideration:

a) One of the basic assumptions of the Fraunhofer line-depth method is that the incident radiation at the instrument is identical in intensity and make-up as the incident radiation at the target. Perhaps even more basic is the assumption that the incident radiation measured by the instrument (components " $\mathrm{A}$ " and " $\mathrm{B}$ ") is representative of the radiation stimulating the luminescence. It is well to remember that the instrument is measuring yellow light while the luminescance of Rhodamine WT dye is stimulated largely by green and blue-green light. Any atmospheric change causing a relative change in the proportion of these colors in the sunlight and skylight should cause a change in the luminescence coefficient 


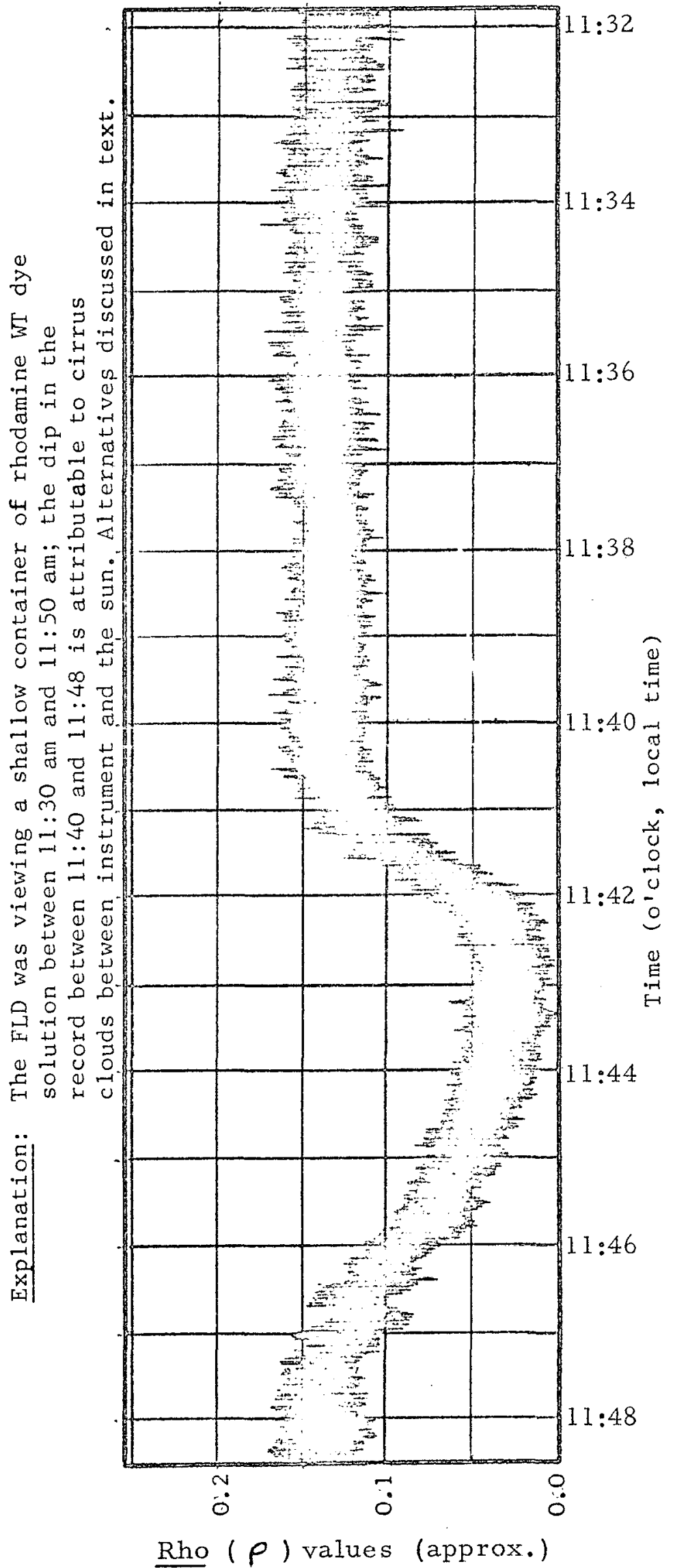


measured by the FLD. Generally, such a change would be evident by a change in the color of the sun, as observed when smoke crosses the sun or as the sun nears the horizon. The fact that cirrus clouds seen to have no effect on the color of sunlight seems to rule out the possibility that this is the source of error. Also, experiments by shading the tank of dye in various ways established the fact that the blue sky itself seems to make no measureable contribution to the luminescence of Rhodamine WT dye solutions, thereby ruling out this factor as the source of error.

b) The alternative explanation is that of computer error within the FLD when it is not in perfect adjustment. This type of error could be largely corrected by use of the standard target, requiring that it be viewed as frequently as once every minute when cirrus clouds or haze were noted between the instrument and the sun. During further tests it will be assumed that this is the source of the error. PLANS FOR FURTHER TESTING OF FRAUNHOFER LINE DISCRIMINATOR AND ANTICIPATED RESUL'TS

Plans for further testing and for implementing the contract objectives are outlined in some detail in the following pages, the organization adhering generally to that of NASA Inter-Agency Order T-80\%85, statement of work for FLD flight testing.

In addition to the principal factors listed, other factors deserving further thought and/or qualitative observation during future tests, but not specifically 
planned for evaluation at this time irclude variation in solar intensity, variations in roughness of the water, dissolved salts in the water, scattering of light in the water, variations in reflectivity of the bottom, reflection of luminescence emission downward from the water surface, absorption of luminescence in the air, variations in viewing angle of the FLD, variations in angle of the light collector, and differences between solar intensity at the instrument and at the target.

A recommendation of the designers of the instrument (Ludwig, Markle, and Schlesinger of Perkin-Elmer, written commun, 1968) deserves emphasis:

"This will be the very first airborne instrument to employ the Fraunhofer line technique to sense solar stimulated luminescence. During the design, considerable care and at:iention were taken in order to minimize known sources of electrical or optical errors. For example, in order to minimize the effect of rapid spectral changes in the background radiation, the two filter packages have been made with components as nearly identical as possible, with minimal responses in the wings of each filter and with the centers of the two filters separated from each other by only a few angstroms. Similarly, computer errors have been reduced until they are comparable to the system shot noise. This was done by the use of a constant temperature thermal enclosure and an adjustable correction system for the critical analog units. However, the unexpected should be anticipated, particularly with the first-of-a-kind airborne unit which does not have even a close relative in the laboratory. If any unexpected limitations are discovered during testing and use of the equipment it is essential that these be clearly identified and documented so that second generations of this equipment can be constructed to take full advantage of this very new and promising technique."

Testing of threshold sensitivity

In general terms, this is roughly equivalent to the minimum luminescence signal detectable, from zero background, as opposed to incremental variations from some background other than zero. This is closely related to electronic 
noj.se (below), because the sensitivity of the FID is limited by the noise associated with the finite number of photons which can be collected per unit time, and also by the accuracy of the multiplication and subtraction. processes used to calculate the luminescence coefficient (Narkle, Ludwig, and others, written commun., Nov. 26, 1968).

1) Tank test. - Determine initially in tank of clear water, by carefully monitoring zero level over period of several minutes, optimizing light collector or other conditions to obtain minimum noise in FLD record, and adding dye in amounts equivalent to about $0.1 \mathrm{ppb}$ increments. To be done during hour from 11:30 to 12:30 for best results. View of tank to be cut off during all stirring operations and dye to be added at point far from view. When dye is detectable, no more to be added, tank to be adequately sampled, and FID allowed to view tank for several minutes. Then allow it to vicw clear water in a shallow container for several minutes to serve as comparison.

2) Airborne verification. -- At outermost detectable fringe of a dye patch, lower string of sample bottles from helicopter to verify actual concentration vs. depth, and correlate with corresponding value of rho measured by FID.

3) Theoretical expression (graphical or mathematical). -- Calculate from above results the threshold sensitivity expressed in terms of sensitivity to Iuminescence from specific concentrations of Rhodamine WT dye under varying conditions: -- varying depths, temperatures, sun angles, turbidities. Express in such a way that sensitivity for all other conditions can be calculated. Also relate to instrumental variations from time to time, and give probable range in threshold sensitivity with differing performance. 
Testing of linearity of output as function of Iuminescence signal

In effect, this is equivalent to plotting a curve of rho values measured by FID Vs. Iuminescence intensity.

1) Tank test, alternative approaches. $\cdots$

a) First approach would utilize increasing quantities of Rhodamine WT dye during a short period of constant conditions: - constant sun angle, constant temperature, constant solar intensity. This approach assumes a straight linear relation of lumimescence intensity to concentration of dye, an assumption that is valid only if no significant attenuation of light occurs outside the fie?.d of view. Therefore the test would require use of a containen that rery closely filled field of view of FID.

b) Second approach would utilize a vary:'ng aperture between lower portal of FID and target, to vary Iuminescence intensity in same way that a fluorometer varies excitation source intensity. The second approach would require a high degree of accuracy in preparing the templates or in measuring their area. 2) Tank test, alternative procedures. $\cdots$

a) During a short period of nearly constant conditions of sun angle, temperature, and solar intensity, increase concentrations of Rhodamine WT dye in uniform increments in the range from about $0 \mathrm{ppb}$ to $25 \mathrm{ppb}$, using approximately 25 equal increments. The dye should be viewed in a fairly shallow container (no more than $1 / 2$ meter deep) having dimensions only slightly larger than the field of view of FWD. The depth will be constant, and the view cut off during addition and stirring 
operations. Purpose of vertical container, which should be an acrylic resin (lucite) cylinder, is to minimize attenuation of light before reaching the target. Calculation will still be required to account for attenuation of luminescence on an upward path through the dye to the lower portal. Because of the above limitations this approach will give only an approximation.

b) Procedure using varying apertures in front of FLD portal while instrument views a tank of dye will have potential errors due to optics, such that an aperture twice the size of another will not necessarily double the effective luminescence received. Therefore, a fixed circular aperture smaller than field of view will be emplaced; this will be exactly bissected in 8 compass directions while noting the FLD readings, then quartered in 8 directions, then cut into octaves, and so forth. The mean value during each series of 8 readings will be used in computing output ( $\underline{\text { rho }}$ ).

3) Airborne verification. -- A comparison of FLD recordings of $\underline{\text { rho }}$ values with corresponding concentrations in water samples from various depths, will give a very rough approximation or verification of conclusions from tank tests. However, these will involve numerous other variables and will not definitively establish linearity or departure from linearity.

4) Theoretical or graphical expression. -- A curve of rho values (i. e., luminosity) measured by FLD plotted against amount of luminescence will show linearity or lack of it. This will be obtained from the aperture 
test, repeated a sufficient number of times to give reproducible results.

\section{Testing of electronic noise}

In effect this will consist of evaluating the amplitude of background noise in the FLD record in relation to pertinent factors. The rapid jitter evident on the recorder tracings is the effect of photon noise, whereas abrupt offsets in the zero position are spurious effects attributed to errors in the analogue computer (Markle, Ludwig, and others, written commun。, Nov. 26, 1968) Decreasing levels of solar intensity have been found to result in increasing noise in the recorded values of luminescence coefficient due to infilling of $B / A$ ratio as it approachis unity. Consequently, small differences in tho become more difficult to cetect as light levels approach the photon noise limit of the instrument. Therefore the noise factor is related to minimum detectable incremental variations in luminescence signal (discussed below).

1) Tank tests.-- The amplitude of noise in the background record will be related to all pertinent external factors and those internal factors that are controllable, as follows:

a) Relation to light collector situation:

1) Changes in position with respect to upper portal

2) Changes in length of tube (lucite cylinder)

3) Changes in size of horizontal white diffuser plate

b) Relation to light collector used:

1) All light collectors will be tried

2) A translucent globe over one or more light collectors will be tried 
c) Relation to $\mathrm{Hz}$ bandwidth setting on electronic console

d) Relation to sun angle and time of day

e) Relation to solar intensity, atmospheric haze

f) Relation to solar $\mathrm{B} / \mathrm{A}$ ratio

g) Relation to intensity of luminescence

h) Relation to amount of reflectance

i) Relation to warm-up time

j) Relation to length of time in use

k) Relation to aircraft vibration

1) Relation to instrument adjustment and sensitivity

2) Airborne verification. -- Factors best evaluated during airborne use will be so evaluated. These will probably include (letters correspond to foregoing list):

h) relation to amourit of reflectance (especially from water)

k) Relation to aircraft vibration

m) Relation to instrument angle with respect to sun

Other factors among those listed above will be evaluated during airborne use as feasible.

3) Presentation of data. -- A simple graphical presentation showing apparent relation of noise to all pertinent factors will be prepared. This may suggest ways to reduce noise level, the procedure possibly varying with time of day. For example, a modification of the light collector at certain times of day may be indicated, and noise may impose 
certain. limits on hours (sun angles) of most effective use, or length of time of uninterrupted use.

Testing of minimum detectable incremental variations in luminescence signal

1) Tank test. -- To be determined by dye concentration runs, varying concentration of Fhodamine WT dye in the range from approximately 0 to $40 \mathrm{ppb}$. Increments of $1 \mathrm{ppb}$ will be used initially, with smaller increments if appropriate. Concentration will be determined by accurate measurement of the final tank concentration, by ascertaining that dye increments are uniform, by adding dye in a controlled manner at a point distant from the instrument, by thorough stirring, and by cutting off view of FLD while adding and stirring is in progress. 2) Airborne verification. -- Correlation of measured rho values with concentration of samples obtained simultaneously; if possible, comparison of rho values at time of two successive samplings within a short time interval at same place. This will provide a very rough verification, only. 3) Appraisal of operator or interpretor discrimination of detectable increments. -Since a major component of this is minimum increment in rho value detectable by an interpretor from the FLD record, this will have to be objectively appraised by obtaining judgment of relative rho values by several persons from real FLD records of known dye concentrations. 4) Alternative procedure for tank tests. -- A more definitive test than the addition of equal increments of dye may be a random change in concentration, upward and downward, by including a dilution process 
in the testing procedure. This could be accomplished by adding clear water by siphon from aerated containers and removing dye by a siphon either simultaneously or after mixing. The dye would be removed from FLD end of tank, the water added at a level midway in tank, at opposite end, and sampling at intervals would be near FLD. This would give a continuous and fairly smooth change by comparison with previous procedure. 5) Presentation. - A graph of luminescence coefficient vs. dye concentration.

\section{Testing of instrument drift}

This consists, in effect, of recording changes in zero level and/ or sensitivity of the FLD with time. During tank tests to date the B/A ratio has remained fairly consistent for those days when the tests were continuous from early morning to late afternoon. A very gradual increase in the ratio during each day could be attributed to instrument drift (Hemphi11, 1968). 1) Airborne and rank test.-- Drift will be determined by means of standard targets consisting of small cylindrical containers of Rhodamine WT dye solution to be viewed by the FLD at frequent intervals (approx. 15 minutes) all day and whenever in use. This will be used to continuously calibrate instrument in the same way that standards are used to calibrate any fluorometer during each use and sometimes at several times during a single use. 
Drift will be related to pertinent factors such as:

a) Number of hours of use, from turnmon

b) Number of hours of use since adjustment

c) Amount of airborne time

Drift in sensitivity at two levels of Iuminescence signal intensity will. be provided by two standard targets containing different concentrations of dye. Drift in zero level will be determined by some other target such as plain water, or by cutting off view of water by an opaque shield. Use of these targets during airborne testing will require mounting of FID within reach of aircraft door, otherwise most of this testing will be Iimited to sround tests.

2) Presentation of data. $\rightarrow$ Simple graphical presentation of drift vs. time during any known conditions considered to be pertinent. This may indicate best means for limiting or minimizing drift, and reguired frequency of tune-up.

\section{Testing of effects of temperature and vibration}

This consists of testing effects on FID function, but also effects of temperature in relation to dye Iuminescence. The photomitiplien tubes have been tested by the manufacturer. They were subjected to vibration of $5 \mathrm{~g}$ 's from 15 to 500 CPS and a displacement of 0.25 inch from 5 to 15 CPS along the major axis of the tubes. The complete optical unit was also subjected to vibration tests $(5,-500-5 \mathrm{~Hz})$ but no vibration effects were observed (Ludwig, Markle, and Schlesinger, 1968, written commun.). 
1) Ground tests.-- Possible relation of instrument temperature to drift in zero level or to drift in sensitivity will be investigated by monitoring both changes and seeking to explain drift in terms of any pertinent factors. Changes of a diurnal nature will be suspected of resulting from temperature change. This will be verified by placing instrument in shade and by earlymorning operations if feasible. Temperature will be measured in some standard manner. These tests will be incidental to other tests, and since the effects will be minimized whenever possible the results are not likely to be definitive in this case. Temperature effects will actually be minimized when possible by shielding the FLD with an insulating jacket, and possibly painting it white.

2) Airborne tests.-. Correlation of instrument drift with hours of airborne: operation, and consideration of other possible factors (temperature, hours since tune-up, etc.) will give possible indications of vibration cffect. 3) Tests of temperature dependence of dye luminescence.-- Tank temperature will be measured at frequent intervals, as will temperature of standard targets. These measurements, when correlated with FLD measurements of rho, will provide means for graphing temperature vs. luminescence intensity. This will be compared to curves previously published, and appropriate correction coefficient derived. 


\section{Testing effects of altitude and field-of-view}

Altitude could conceivably be a factor in relation to the geometry of the viewing angle and the field-of-view, and therefore the latter factor is appropriate to consider here. Altitude will also be a factor in relation to atmospheric attenuation of light between target and instrument.

Theoretically neither altitude nor field-of-view should need to be considered in the geometry of the problem but this may need to be demonstrated by tests. As long as the total field of view is filled by the target, and the concentration is uniform, the luminescence coefficient should remain constant no matter what the distance between sensor and target. This results from the fact that luminescence originates from a nearly infinite number of points and is radiated outward in every direction (i. e., is not collimated), hence the intensity should be nearly constant as long as the field of view is filled. Therefore the same proportion of luminescence should be sensed from all depths no matter what the altitude, field-of-view, and angle of view; and the same amount should be sensed from all depths no matter what the altitude and field-of-view.

In relation to factors other than geometry, however, the effect of altitude deserves testing because of its importance to future use of this remote sensing technique from high altitudes and eventually from orbital altitudes.

The FLD instrument housing has already been tested by the manufacturer to a simulated altitude of 90,000 feet for a duration of 15 minutes. At low 
pressure the j.ndicator switch installed in the housing showed that a minimum pressure of 0.07 atmosphere was attained and maintained without deformation upon return to ambient pressure (Ludwig, Markle and Schlesinger, 1968, written commun.). The release valve must be used to release the cover.

1) Airborne tests. - one or more of three alternatives:

a) If it were necessary to demonstrate that altitude and angle of the field-of-view are not significant factors in relation to geometry, this would be done on an exceptionally clear day, when target and sensor are very uniformly illuminated. The FID would be aimed as closely as posiible at a certain spot in a patch of well-dispersed dye, and the aircraft would rise to increasing altitude, while changes in luminescence coefficient were noted. If no significant change were noted this would be interpreted as a denomstration that altitude and field-of-vier are not significont geometric factors. If a change were noied, it would be assumed that a change in distribution of dye had occurred, which would be verified by descending under similar conditions and comparing with original values.

b) An alternative would be to view a know concentration of dye enclosed in a plexiglas box at the water surface, and rise above it, recording rho values only when the box was entirely within the field of view; this would be at altitudes above 500 feet with the present box ( $5 \mathrm{ft} . \mathrm{x} 5 \mathrm{ft.}$ ). The same could be done with the box submerged, but neither test a) or b) is anticipated as necessary. 
c) A more useful alternative will be to test feasibility of sensing by means of qualitative technique suitable for high-altitude aircraft or orbital altitudes. The equivalent of a C/D ratio will be monitored by the FLD, by one of three alternative methods, while making repeated crosstraverses of a patch of Rhodamine WT dye from a high altitude (i.e., within upper part of safe range for the H-19): 1) by re-wiring FLD to compute C/D instead of rho; 2) by recording $C$ and $D$ from respective phone jacks and computing the ratio by hand, point to point; and 3) by using instrument upside-down, in which case $\mathrm{B} / \mathrm{A}$ ratio becomes $\mathrm{C} / \mathrm{D}$. The latter method is preferred for its simplicity, but has the disadvantage that the $4: 1$ split of the light beams will reduce the luminescence signal to $25 \%$ of its potential level. Since this would only be a test of the method, however, the beam-splitting ratio may allow useful data to be collected, although increased noise levels may limit sensitivity drastically. The portal facing the sky would probably be covered or used for an unrelated test, taking care to reduce light in proportion to the $4: 1$ ratio.

2) Tank tests and ground tests.-- Tests will consist of accurately defining the field-of-view to permit accurate calculation of the outward angle of the FOV and size of the target being sensed from various altitudes. A diaphragm or improvised device of comparable design will be closed around the field of view while FLD is viewing a tank of dye. The point at which the rho value begins to show a change will define the field-of-view. This will be carried out at several levels below the instrument as a double check and will be repeated until reproducible results are obtained. It cannot necessarily be assumed that the field of view is exactly circular, or exactly vertical, or if circular that it is exactly symnetrical with respect to luminescence intensity. 
and moving a small light behind a diaphragm.

\section{Testing of effects of haze and clouds}

1) Ground tests or tank tests. -- Effects of variations in solar intensity due to haze and clouds will be evaluated on a cloudy or hazy day, by monitoring component $A$ on the recorder, as well as rho. For constant sun angles, changes in solar intensity associated with clouds or haze theoretically should not effect rho values. The magnitude of changes will be more accurately assessed by use of standard targets. If it is evident that significant changes in tho are produced by changes in solar intensity it will be necessary to modify operating prccedures. These modifications will probably consist of monitoring component A continuously while FLD is in use, and possibly checking more frequently against standard targets. It will also be necessary to determine the relation between variations in component $A$ and variations in $\underline{r h o}$, and to establish whether or not these variations are also a function of sensitivity, which is known to be variable. These determinations may be the highest-priority tests, since all other relations would be affected.

2) Airborne tests.-- Similar procedures as above, consisting of monitoring component $A$ and noting dependence of $\underline{\text { rho }}$ on these variations. Airborne tests will be primarily a verification of the tank tests, but will also need to be used operationally if there is a dependence of rho on "A" levels. 3) Presentation.-- Graphical presentation of dependence of luminescence coefficient ( $\underline{\text { rho }}$ ) on "A" for a given value of sensitivity coefficient ( $\mathrm{S}_{\mathrm{c}}$ ). Similar graphs for other values of sensitivity, if possible. Recommendations will be needed on how to cope with this problem operationally. 
These may require experimentation to determine which components of rho (e.g., C or D) cause the malfunction, by separately recording $C$ and/or D.

\section{Testing of effects of sun angle}

Tests of the effect of sun angle with respect to light collector will first be conducted over a tank, by artificially tilting the instrument and noting change in rho values. Evaluation will also, require consideration of relation between instrument viewing angle and target. But since there is no practicable method for measuring aircraft angle during tests the preferable approach will be to use a globe or to keep view as nearly vertical as possible, and to assume it is vertical.

1) Ground tests.-- To include accurate recording of time, and approximate? measurement of sun angles with sufficient frequency to establish an accurate curve of sun angle vs. time for each day the tank tests or airborne tests are in progress. The Nautical Almanac can be used instead, but measurements on the ground are simple, sufficiently accurate, and free of error. Verification of theoretically predicted effects will be accomplished by viewing a tank or other container of constant dye concentration during one day (while other tests are in progress). The standard targets would be unsuitable for this purpose because the planned dimensions (approx. equal to field-of-view) effectively eliminate dependence on sun angle.

2) Airborne tests.-- Tests will be intended to verify the predicted effects determined from ground tests and, besides evaluating effect of sun angle with respect to target, will evaluate effect of sun angle with respect to light collector. If the latter proves significant it will be necessary to minimize effect of aircraft angle (i.e., light-collector angle with respect to sun) by adding a translucent sphere over the light 
collector.

Testing of signal noise in crossing targets of varying reflectivity Materials anticipated will include concrete, asphalt, water, soil types, foliage types, and man-made structures. It should be noted that the manufacturer peaked the instrument to optimum sensitivity and tested a variety of materials but found no detectable departure from rho of zero for black painted wood, new wood, white concrete, green grass, hemlock, and tamarac (Markle, D.A., written commun., Apri.1 18, 1968).

1) Ground tests. -- Tests of various materials to date by USGS showed little variation except when objects were so orien;ed that they produced specular reflection as seen from the direction of the: instrument, and when so oriented even a sinall crystal face produced large values of rho. Such tests are of little value as applied to airborne use, hence no further ground tests of this type are contemplated.

2) Airborne tests. -- Emphasis will be on variations over water of varying roughness. Any variations encountered over land will be noted and investigated in detail to determine precise source of the anomalies. Recording chart will be closely monitored in flight for anomalies, with the object of identifying sources of luminescence in the yellow region of the spectrum. Particular attention will be given to sustained anomalies such as might be encountered over water, and efforts will be made to determine what factors contribute to any such anomalies with the object of deriving any available information from this signal. 
Testing dispersion characteristics of Rhodamine WT dye in water

1) Airborne tests in shallow water.-- Vertical and horizontal dispersion are equally important in interpretation of FLD data. Tests of dispersal in the shallow water of Bolinas Lagoon will be mainly of a qualitative type, involving detection and tracing of dye as it disperses from various points. This will be a test of the applicability of the ELD to tracing the direction and velocity of current movement and the patterns of circulation of water in bays and estuaries, and also a test of dispersion characteristics of the dye.

2) Airborne tests in deep water.-- Tests w:Il consist essentially of monitoring a patch of Rhodamine WT dye as $i$ i: spreads from the place of origin. This investigation will be facilitated by initially attempting to obtain a nearly uniform dispersal with depth. Vertical dispersal will be verified by samples at 2 or 3 (or more) depths at intervals, and by FLD measurements correlated with these samples. Horizontal dispersal will be determined in a similar manner.

Testing luminescence signal as a function of depth in water of the luminescence-producing dye

1) Tank tests.-- Tank tests of depth vs. luminescence signal have already been conducted in the depth range up to $\frac{1}{2}$ meter. These will be continued by means of lowering an opaque shield through a tank of dye being sensed and by draining the liquid from a tank of dye being sensed, but these have a low priority by comparison with airborne tests involving much deeper water columns.

2) Airborne tests.-- Planned tests will use a plexiglas tank filled with a dye solution and lowered to known depths, as iliustrated by 
Figure 12. Interpretation will require certainty that the FLD was aimed exactly at the tank of dye. This will require that the field of view be swept back and forth across the region of the box until the rho reading is maximized, while the depth of the box is kept steady. The sides of the box should be opaque, otherwise interpretation will not be accurate. In effect, the plexiglas box experiment will measure attenuation of incident plus emitted light by natural water and turbidity conditions, in a manner permitting an unambiguous interpretation. Methods described under the next heading are intended to give comparable data during operational use of the FLD.

Testing attenuation of incident radiat: on and luminescence emission as a function of $d \epsilon$ pth

Absorption and scattering of light will be combined into a single measure of attenuation coefficient. In effect, this is the major operational problem in use of the FLD for measurement of dye concentration. The planned procedure for the complete test will approximate operational use of the instrument and typically will include most of the following steps:
a) Adjustment (tune-up) of FLD
b) Warm-up (e.g., in hangar near plane, if practicable)
c) Prepare constant-temperature water bath or insulated container for standard targets (optional)
d) Check temperature of standards
e) Calibrate FLD against standards
f) Check sun angle prior to flight, and accurate time for all readings
g) Check zero level over open water
h) Check sensitivity to aircraft tilt 


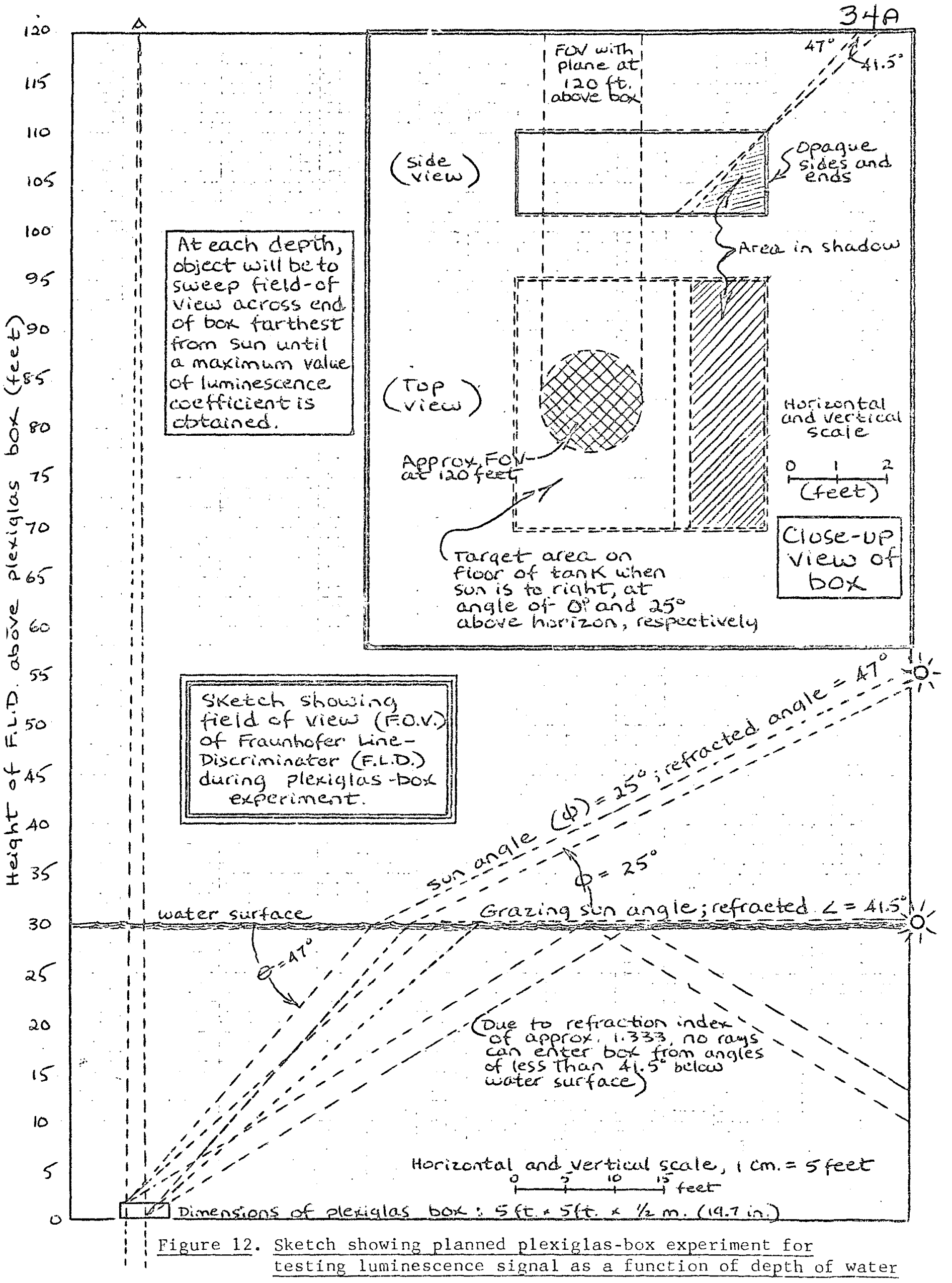


i) Check aim of aiming tube and adjust

j) Check calibration against standards at frequent intervals no greater than 15 minutes during flight, and whenever sensitivity change is suspected, or shift in zero level is suspected.

k) Lower sample bottles into clear water for temperature test and possibly for approximate turbidity test.

1) Drop dye in deep water using pre-arranged system for good vertical dispersal.

m) Lower string of sample bottles into center of dye patch.

n) Note FLD readings as close as possible to moment of sampling and place of sampling, checking ain with tube.

o) Calibrate with standard targets immediately after sampling and recording tho values.

p) Withdraw sample bottles, transfer to other containers, taking watar temperature immediately after retrieval.

q) Continue rho readings during cross-traverses over dye patch, estimating position of edge as it spreads.

r) Document with photography of edge detectable by fLd (color and black and white) for comparison with photodensitometric method (Ichiye and Plutchak, 1966).

s) If sampling procedure is successful, continue to monitor dispersal with depth at frequent intervals, and to verify concentrations.

t) Continue as above as long as results are suitable and FLD performs satisfactorily.

u) End airborne test with water sample string and calibration of FLD.

v) On ground, check sun angle and time. 


\section{CONCLUSIONS}

1) Smallest detectable dye concentration increments in $\frac{1}{2}$-meter depths were approximately 1 part per billion, varying with instrumental sensitivity at the time of each test and depending partly on ability to visually differentiate small steps in the record of rho against background noise. It can be inferred that increments considerably smaller than 1 ppb would be detectable in depths considerably greater than $\frac{1}{2}$ meter.

2) Tests showed that illumination of the dye column sensed by the FLD is more important in determining rho values than how much dye is in the column, although the two are interrelated.

3) Therefore attenuation coefficients for light are the principal factors to be considered in intetpreting FLD records.

4) Tests in which attenuation of emitted light is isolated from that of incident liglt show a nearly direct proportionality between rho values and emitted light intensity for varying depths, indicating that only an insignificant amount of attenuation is attributable to that of emitted light, by the dye.

5) An undisturbed cylinder of turbid dye solution ( $70 \mathrm{ppb}$ ) $\frac{1}{2}$ meter deep was found to have no luminescence detectable by the FLD after settling 24 hours. This is interpreted as due largely to absorption and scattering of light by the suspended sediment because nearly complete restoration of luminescence was recorded by laboratory fluorometer after settling of the uppermost $2 \mathrm{~mm}$. of liquid.

6) An apparent correlation was found between length of the light collector tube and background noise levels in the record of rho, suggesting that experimentation with the light collector may improve the signal-to-noise ratio. 
7) Occasional spurious stifts are evident in recorded values of rho, these generally being obvious at the time of occurrence, allowing correction by monitoring a standard target.

8) A brief airborne test in an H-19 helicopter established feasibility of operating the FLD from a 115-volt generator powered by the plane and established that the rotor blades do not visibly effect the $B / A$ ratio.

9) The FLD has an advantage over conventional dye sampling and fluorometer analysis in that it adds the dimension of depth, and it can be done remotely from an aircraft.

10) On clear sunny days the optimum tine for sensing with the FLD

will be during the 2 -hour period centering it midday. Sensitivity appears greatest at highest sun angles, and therefore the best time of year north of latitude $23 \frac{1}{2}^{\circ} \mathrm{N}$. should be near June 21 from the standpoint of sun angle alone.

11) Tests of temperature-dependence of fiuorescence have shown that this factor is significant and should not be overlooked in quantitative use of the FLD. When temperature variation with depth is known the average should be weighted to correspond to the average depth from which luminescence emanates.

12) Tests of the relation between reflectance of target materials

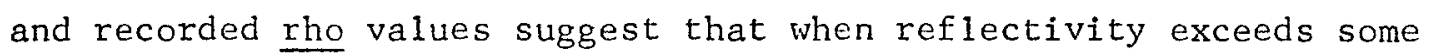
citical limit the computer cannot cope with the signal and a spurious rho value is recorded. This limit appears sufficiently high that reflectivity is not likely to be a problem over water.

13) A probable limitation in operational use of the FLD will be the fact that imperfect adjustment apparently results in appreciable 
dependence of rho on intensity of solar radiation. This is likely to be a frequent occurrence, requiring that solar intensity be monitored (by components $A$ or $B$ ), and that abrupt changes be accompanied by frequent calibration with standards.

14) Observations have established that the sky itself makes no appreciable contribution to the luminescence of Rhodamine WI dye solutions, by comparison with direct sunlight.

15) The ratio $B / A$ remained fairly constant from early morning to late afternoon, generally increasing very gradually as a probable result of instrument drift.

16) More work is needed to define the relation between turbidity and luminescence, particularly in terms of attenuation coefficients, and also in terms of adsorption of Rhodamine WT dye on suspended sediment of various grain sizes.

17) The greatest need for data on adsorption losses is in the concentration range from 0 to 10 parts per billion, in the time range from 0 to 24 hours, in the grain-size range of clay and silt, and the turbidity range equivalent to attenuation coefficients from $0.10 \mathrm{~m}^{-1}$ to $0.50 \mathrm{~m}^{-1}$.

18) There is a probable need for a coefficient of luminescence loss, expressed in percent per hour, to combine losses from adsorption, exposure to light, photo-chemical deterioration, and other calises. Experimental work to define the limits of each for Rhodamine WT dye is needed.

19) Experimental or theoretical work is recommended to relate some of the following factors to FLD function: a) solar intensity; b) rough- 
ness of the water; c) dissolved salts in the water; d) scattering of light in the water; e) reflectivity of the bottom; f) reflection of luminescence emission downward from the water surface; g) absorption of luminescence in the air; h) viewing angle of the FLD; $i$ ) angle of the light collector (diffuser plate); and $j$ ) differences between solar intensity at the instrument and at the target. 


\section{REFERENCES CITED}

Carpenter, J.H., 1960, Tracer for circulation and mixing in'natural waters: Public Works, vo1. 91, p. 110-112.

Hemphill, W. R., 1968, Remote detection of solar stimulated luminescence: 19 th Congress of the International Federation, Amer. Inst. Aeronautics and Astronautics, Special Pub. no. AS 156, 6 p.

Ichiye, T., and N. B. Plutchak, 1966, Photodensitometric measurement of dye concentration in the ocean: Limnology and Oceanography, vol. 11, p. 364-370.

Stoertz, G. E., 1969, a, The Fraunhofer Line Discriminator, an airborne fluorometer: U. S. Geol。 Survey Open-File Report.

Stoertz, G. E., 1969b, Fraunhofer line-depth sensing applied to water: U. S. Geol. Survey Open-File Report.

Watt, J. P. C., 1965, Development of the dye dilution method for measuring water yields from mountain watersheds: Thesis, Colorado State Univ., Fort Collins, Colorado. 